\title{
EL FRACASO DE LA CONTINUIDAD. LA ECONOMÍA POLÍTICA DEL SEXENIO DE ENRIQUE PENA NIETO
}

\author{
THE FAILURE OF CONTINUITY. POLITICAL ECONOMY \\ IN THE ENRIQUE PEÑA NIETO ADMINISTRATION
}

\section{L'ÉCHEC DE LA CONTINUITÉ. L'ÉCONOMIE POLITIQUE SOUS LA PRÉSIDENCE D'ENRIQUE PEÑA NIETO}

ILÁN BIZBERG

El Colegio de México

ilan@colmex.mx

Resumen: La presidencia de Enrique Peña Nieto pretendió dar un giro de 180 grados al hecho fundamental que había marcado al gobierno anterior, la guerra en contra del crimen organizado. Para ello, decidió concentrarse en lo que llamó las reformas económicas estructurales, lo que significaba extender el modelo implementado desde los años ochenta, y que había seguido imperturbable durante los siguientes cuatro sexenios. Ello, a pesar de que durante los últimos treinta años el desempeño de la economía mexicana, así como sus efectos socioeconómicos, han sido muy decepcionantes. Esto es aún más claro si tomamos en cuenta las excepcionales condiciones en las que se desarrolló la economía internacional entre el año 2000 y 2014, en lo que se ha conocido como el superciclo de las commodities, caracterizado por un crecimiento acelerado de China, que estimuló enormemente la demanda y el precio de las materias primas, así como por la expansión de los recursos financieros provenientes de Estados Unidos, que llevó a la mayoría de los países de Latinoamérica a crecer de manera más acelerada y, sobre todo, a hacerlo al tiempo que disminuían la pobreza y la desigualdad. En contraste, México no logró aprovechar las muy favorables condiciones económicas internacionales para mejorar la situación socioeconómica de su población.

Palabras clave: economía política; sexenio Enrique Peña Nieto;

México; crecimiento; desigualdad. 
Abstract: The presidency of Enrique Peña Nieto was supposed to mark a 180-degree turn with respect to the dominant issue of the previous government: the war on organized crime. To achieve this, a decision was made to focus on structural economic reforms, by expanding the model first implemented in the 1980s and that had continued undisturbed over four governments. This is despite the fact that over the past thirty years the performance of the Mexican economy, together with its socioeconomic impact, has been disappointing. This under-performance is all the more marked in light of the exceptional conditions in which the global economy developed between 2000 and 2014, known as the commodities super cycle. This was characterized by accelerated growth in China that provided a huge stimulus for the demand and prices of raw materials, together with the expansion of financial resources from the United States, which led the majority of countries in Latin America to grow faster and, above all, to do so while reducing poverty and inequality. By contrast, Mexico failed to take advantage of the very favorable global economic conditions to improve the socioeconomic situation of its population.

Keywords: political economy; Enrique Peña Nieto administration;

Mexico; growth; inequality.

\section{Traducción de Gonzalo Celorio Morayta}

Résumé: Le gouvernement d'Enrique Peña Nieto a essayé de s'éloigner radicalement de la politique la plus importante de son prédécesseur, celle qui concernait la lutte contre le crime organisé. À cette fin, il a accordé priorité aux réformes économiques dites «structurelles», ce qui a impliqué le renforcement du modèle adopté depuis les années 1980 (imperturbable le long de quatre périodes présidentielles), malgré le fait que les résultats de l'économie mexicaine et les effets sociaux qui en découlent ont été fort décevants. Ces limitations sont encore plus évidentes si l'on considère les conditions de l'économie internationale dans la période 2000-2014, marquée par l'essor des commodities et par le développement accéléré de la Chine, qui a beaucoup favorisé la demande et le prix des matières premières; en même temps, l'abondance des ressources financières provenant des États-Unis a permis une croissance remarquable dans la plupart des pays de l'Amérique latine, accompagnée d'une diminution de la pauvreté et de l'inégalité. Par contre, le Mexique n'a pas su profiter -pour améliorer la situation sociale 
de sa population- de ces conditions économiques internationales tellement favorables.

Mots clefs: Économie politique; gouvernement d'Enrique Peña Nieto;

Mexique; croissance; inégalité.

Traducción de BERnARDo Mabire

Fecha de recepción: junio de 2019

Fecha de aceptación: noviembre 2019

\section{L} a presidencia de Enrique Peña Nieto pretendió dar un giro de 180 grados al hecho fundamental que había marcado al gobierno anterior, la guerra en contra del crimen organizado. Para ello, decidió concentrarse en lo que llamó las reformas económicas estructurales. Durante año y medio pareció tener éxito, al lograr concluir un pacto con los partidos: el "Pacto por México", mediante el cual el gobierno logró llevar a cabo varias reformas a la Constitución, entre las más importantes, la fiscal, la hacendaria, la energética y la educativa. Esto incluso llevó al semanario The Economist a aclamar a su gobierno como el "Momento de México" y a Peña Nieto como el "Salvador de México". ${ }^{1}$ No obstante, el impulso reformador de Peña Nieto duró apenas año y medio, porque su imagen colapsó con un asunto de corrupción en el cual estuvo involucrado el presidente y su esposa, y fracasó su intención de silenciar la grave crisis de violencia por la que pasaba el país, con el terrible secuestro y asesinato de los 43 estudiantes de Ayotzinapa. A partir de ese momento, se limitó a administrar el gobierno.

En términos económicos, se concentró en extender el modelo implementado desde los años ochenta, y que había se-

1 "Mexico's Moment", The Economist, 21 de noviembre de 2012 https://www.economist.com/news/2012/11/21/mexicos-moment y "Saving Mexico", Time, 24 de febrero de 2014. 
guido imperturbable durante los siguientes cuatro sexenios. La única diferencia que marcó el sexenio que nos ocupa es su intento por profundizarlo. La reforma más importante en el aspecto económico fue la energética, que abrió el sector al capital privado. La más significativa en términos sociopolíticos fue la educativa, que se propuso eliminar la influencia de los sindicatos de maestros (SNTE y CNTE) en las decisiones de otorgamiento de plazas laborales. Ambas medidas intentaban completar el abandono del modelo socioeconómico mexicano de sustitución de importaciones y un modelo sociopolítico corporativista, aunque tuvieron un efecto muy moderado (si es que tuvieron alguno) sobre la economía mexicana.

Durante los últimos treinta años, el desempeño de la economía mexicana, así como sus efectos socioeconómicos han sido muy decepcionantes. Esto es aun más claro si tomamos en cuenta las excepcionales condiciones en las que se desarrolló la economía internacional entre el año 2000 y 2014, en lo que se ha conocido como el superciclo de las commodities, caracterizado por un crecimiento acelerado de China, que estimuló enormemente la demanda y el precio de las materias primas, y por la expansión de los recursos financieros provenientes de Estados Unidos a partir de la crisis del internet a inicios de la década de 2000 y, sobre todo, a partir de la crisis global de $2008 .^{2}$ Esto llevó a la mayoría de los países de Latinoamérica a crecer de manera más acelerada y, sobre todo, a hacerlo al tiempo que disminuían la pobreza y la desigualdad. En efecto, por primera vez desde la industrialización por sustitución de importaciones (ISI, ocurrida de la década de 1940 a la de 1970), el crecimiento en Latinoamérica estuvo acompañado por una disminución de la pobreza y de la enorme desigualdad que sigue caracterizando a este continente. ${ }^{3}$ De hecho, uno de los rasgos del modelo de de-

${ }^{2}$ Robert Boyer, "Is More Equality Possible in Latin America? A Challenge in a World of Contrasted but Interdependent Inequality Regimes", desiguALdades.net, Working Paper Series 67, Berlín, Freie Universität Berlin, 2014.

${ }^{3}$ Boyer, Loc. cit.; Göran Therborn, "Moments of Equality - Today's Latin America in a Global Historical Context", en Barbara Fritz y Lena 
sarrollo que adoptaron muchos países latinoamericanos durante el superciclo de las materias primas fue redistribuir para sacar a la población de la pobreza y hacer crecer a las clases medias para expandir el mercado interno e impulsar un crecimiento guiado por los salarios.

\section{GRÁFICA 1}

Estratificación social en América Latina

(\% de variación, 2000-2013)

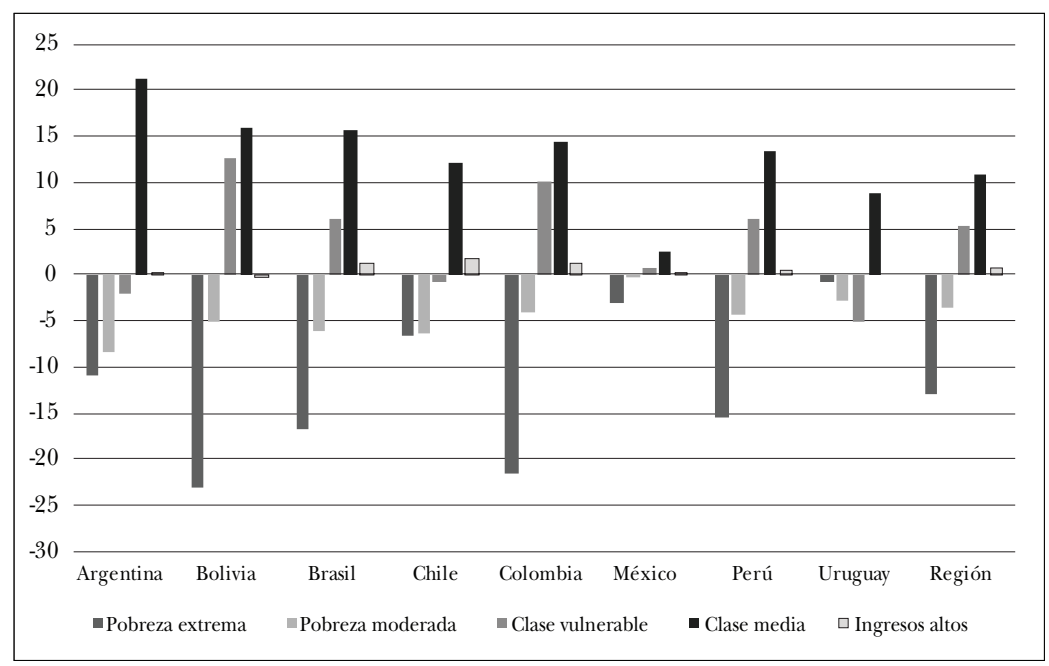

Fuente: Marco Stampini, Marcos Robre, Mayra Sáenz, Pablo Ibarrarán, Nadin Medellín, "Pobreza, vulnerabilidad y la clase media en América Latina", Working Paper, núm. 591, BID, 2015, cuadro 1, p. 10.

En esta gráfica es posible ver cómo, a diferencia de los otros países del continente, México no logró aprovechar las muy favorables condiciones económicas internacionales para mejorar la situación socioeconómica de su población.

Lavinas, A Moment of Equality for Latin America? Challenges for Redistribution, Surrey and Burlington, Ashgate, 2015. 
Esta circunstancia se debió a una serie de razones que no pueden discutirse todas en un artículo ${ }^{4}$ centrado en los últimos 6 años de la vida económica del país. No obstante, es importante plantearlo de entrada en la medida en que el sexenio de Peña Nieto se caracteriza por su total continuidad con el modelo de capitalismo que se implantó desde mediados de los años ochenta.

El presente texto está dividido en dos partes. En la primera formalizamos el tipo de capitalismo mexicano con base en algunas de sus características más notables. En la segunda, analizaremos en qué medida el sexenio de Peña efectivamente es una continuidad del modelo y cómo se preservan sus limitantes más fundamentales: el bajo crecimiento, la exigua creación de empleos de buena calidad y la baja expansión del mercado interno, entre las más importantes.

\section{El CAPITALISMO MEXICANO DE SUBCONTRATACióN INTERNACIONAL ${ }^{5}$}

La economía mexicana es una forma desarticulada de capitalismo que depende totalmente de la demanda de compañías

${ }^{4} \mathrm{Y}$ a las que refiero en mi libro más reciente: Ilán Bizberg, Diversity of Capitalisms in Latin America, Londres, Palgrave, Macmillan, 2019.

${ }^{5}$ Vale la pena recordar que esta caracterización del capitalismo mexicano se ubica en el contexto de una tipología que define cuatro tipos de capitalismos en América Latina. La segunda variedad es una estilización del modo de desarrollo que siguieron Brasil y Argentina desde el comienzo de 2003 hasta 2014, un capitalismo sociodesarrollista. Esta forma se basa tanto en la exportación de commodities, como en manufacturas para el mercado interno. El Estado es un actor fundamental que intenta arbitrar entre, por un lado, la dependencia externa de una economía periférica productora de materias primas, vinculada con el capital financiero y, por el otro, la producción industrial destinada al mercado interno. El modo de consumo también es un compromiso entre ambos: se buscan mercados externos y atraer capitales extranjeros, y se impulsa la industria nacional incrementando la demanda interna a través del aumento de los salarios y de un sistema de protección social generoso. Esta forma depende tanto de 
ubicadas en Estados Unidos u otros países del centro, dado
que es básicamente (aunque por completo) una plataforma
para las maquiladoras que ensamblan piezas importadas y, en

las exportaciones de productos básicos y del aporte de capital financiero, como del crecimiento del mercado interno. El Estado es intervencionista y trata de encontrar un equilibrio entre un modelo de crecimiento impulsado por los salarios (wage led growth) y un modelo basado en las ganancias (profit led growth). Intenta dirigir la economía por medio de una política industrial y del financiamiento al desarrollo. Con el fin de desarrollar la industria, recurre a los recursos externos que provienen de la exportación de productos básicos, ingresos de inversiones extranjeras de cartera, inversión extranjera directa (IED) y deuda. Esta forma capitalista se basa en una sociedad civil fuerte que ejerce presión sobre el Estado para la redistribución, de manera que la relación salarial se caracteriza por políticas salariales expansivas y por un sistema de protección social orientado a la universalidad, que tiende a reducir la desigualdad. El Estado se ve obligado a arbitrar entre el capital internacional, las grandes empresas nacionales, los intereses financieros, los trabajadores, las clases medias bajas y los pobres; entre todos estos sectores se establece un compromiso social.

Los dos tipos de capitalismo restantes se caracterizan por depender totalmente de las commodities y son, por ello, capitalismos rentistas. Aunque el modo de acumulación, la dependencia de las materias primas y la economía externa son similares, hay diferencias significativas con respecto al carácter de la coalición dominante y la relación salarial, la forma en la que se distribuyen las ganancias de la renta. Ello determina que haya dos tipos, uno liberal y otro redistributivo. El primero es una estilización de Perú, Colombia y en parte Chile (porque el Estado chileno es más fuerte), países que comparten una economía extremadamente abierta, un Estado y sindicatos débiles, la desregulación del mercado laboral y un sistema de seguridad social reducido y orientado a la asistencia. La coalición dominante está formada por grandes compañías extranjeras y nacionales, la sociedad civil y parte de las clases medias. El modo de consumo está orientado a las ganancias, se trata de un profit-led growth. Los salarios crecen por abajo de los aumentos de la productividad.

En contraste, en el capitalismo rentista redistributivo, aunque es igualmente dependiente del mercado internacional de commodities, el Estado es intervencionista y posee o cede concesiones de explotación de materias primas a cambio de regalías e impuestos. Esto se debe, en gran medida, a la presión que ejercen actores sociales fuertes sobre el Estado para que intervenga en la economía y redistribuya las ganancias. Las políticas salariales y sociales son expansivas; estas últimas tienden hacia la universalidad. 
algunos casos (como la automotriz), integran componentes producidos internamente, aunque sobre todo por subsidiarias extranjeras de las grandes compañías. Está más conectada con la economía de Estados Unidos que con la estructura productiva doméstica debido a que se añade escasa producción local y poco valor agregado. La conexión se da entre las compañías principales y las subsidiarias, las cadenas de producción son transnacionales. A este tipo de capitalismo lo hemos denominado "capitalismo de subcontratación internacional".

Los productos manufacturados pueden llegar a tener un contenido tecnológico relativamente alto, aunque el valor agregado añadido en el país sea muy bajo, pues proviene básicamente de mano de obra en la última etapa del proceso productivo o en los nichos de la cadena productiva, en los cuales su concentración es alta. Ésta es la razón por la que, aunque México se haya convertido en uno de los más grandes exportadores de manufactura en el mundo, y el mayor en Latinoamérica, el impacto interno del auge de las exportaciones de productos cada vez más complejos ha sido muy limitado. De hecho, las maquiladoras propiamente dichas, que siguen constituyendo alrededor del $60 \%$ de las exportaciones totales, son empresas exclusivamente de ensamblaje, que incorporan una mínima parte de productos nacionales (alrededor del 3\%). También existe un sector de alta productividad, sobre todo automotriz, que compite favorablemente a nivel internacional por la diferencia entre su elevada productividad (similar a la de los países centrales) y sus bajos salarios (comparados internacionalmente) ${ }^{6}$

La competitividad de esta forma capitalista depende de los bajos costos de la mano de obra (tanto salarios como de seguridad social), alta flexibilidad del mercado del trabajo, bajos impuestos y regulaciones ambientales laxas. Es un

${ }^{6}$ José Gabriel Palma, "The seven main 'stylized facts' of the Mexican economy since trade liberalization and NAFTA", Industrial and Corporate Change, vol. 14, núm. 6 (2005), pp. 941-991. 
modelo económico que favorece las ganancias y reprime los salarios (de crecimiento basado en las ganancias más que en los salarios o profit-led-growth más que wage-led-growth ${ }^{7} \mathrm{y}$, por ende, reprime la demanda interna, lo que genera bajo crecimiento, reducida creación de empleo e incapacidad para construir cadenas productivas que integren mayor valor agregado. Es un modelo empantanado en una trampa de lenta (o nula) mejoría del nivel productivo y mejoramiento tecnológico, en claro contraste de cómo se desarrolló la economía coreana y taiwanesa, y como se está desarrollando la economía China; es por ello que en este artículo haremos referencias a estos tres países, así como a algunos otros del continente latinoamericano.

Una característica muy significativa de este modelo es mantener una muy baja presión impositiva. El Estado interviene marginalmente, no aplica políticas industriales, no estimula el mercado interno, por el contrario, reprime los salarios y aplica una política social puramente asistencialista. El Estado no busca activamente la integración de la industria doméstica a la plataforma exportadora, como lo hizo en Corea y Taiwán, o lo intentó Brasil y Argentina entre 2003 y 2014, ni transferencia de tecnología, como lo hace China y como lo hacía el propio gobierno mexicano durante el periodo de la ISI. El Estado mexicano apenas establece las condiciones para que haya inversión privada de cualquier tipo, sin ninguna orientación o proyecto para crear cadenas productivas y aumentar la demanda agregada. De hecho, el Tratado de Libre Comercio con Estados Unidos y Canadá (TLCAN) impone restricciones significativas a la acción gubernamental que limitan considerablemente al Estado mexicano, en comparación con el brasileño o el chino. Además, la ideología de los funcionarios gubernamentales desde me-

${ }^{7}$ Engelbert Stockhammer, "Crecimiento basado en los salarios: introducción”, en Hacia una recuperación sostenible: por una política de crecimiento basada en los salarios, Boletín Internacional de Investigación Sindical, Ginebra, OIT, vol. 3, núm. 2 (2011). 
diados de los años ochenta ha estado por completo en sintonía con dichas restricciones a la acción estatal.

Como hemos sostenido en varios escritos, un modelo económico es resultado de un pacto sociopolítico. En el caso de México este compromiso se produce entre el Estado, las compañías multinacionales, los grandes grupos económicos nacionales, el capital financiero y parte de la clase media que se beneficia del modelo. Los sectores populares están excluidos del compromiso, dado que la sociedad civil (sindicatos, organizaciones sociales) es débil, está poco organizada y no es muy representativa, y el sistema político y la estructura estatal están poco abiertos a sus demandas. Como resultado, el Estado mexicano carece de suficiente autonomía con respecto a los grupos dominantes y de ahí se deriva una estructura económica oligopólica y un entramado político oligárquico. Este compromiso margina a las empresas y a la población que viven del mercado interno, así como a los trabajadores informales y a los pobres.

La fragilidad del modelo de subcontratación internacional es su dependencia de la economía externa, de la descomposición social que resulta del aumento de la pobreza y la desigualdad. A pesar de que el capitalismo mexicano no ha sufrido una crisis abierta desde 1995 y se recuperó rápidamente de la crisis global de 2008, por lo que puede considerarse un modelo sostenible, tiene problemas estructurales fundamentales que permiten afirmar que está pasando por una crisis de baja intensidad, rampante.

El sexenio de Peña Nieto, la continuidad del modelo

La consecuencia más significativa del modelo de subcontratación internacional es el lento crecimiento de la economía del país. ${ }^{8}$ La paradoja es que mientras las exportaciones crecen

${ }^{8}$ C. Ibarra, "La paradoja del crecimiento lento de México", Revista de la CEPAL, núm. 95 (2008); Alicia Puyana y José Romero Tellaeche, México. 
de manera acelerada, la economía nacional no lo hace al mismo ritmo, aunque la estrategia de desarrollo del país basada en la apertura y la creación de las mejores condiciones para la inversión extranjera ha llevado al aumento extraordinario de las exportaciones mexicanas, y que se hayan creado empleos con salarios relativamente altos en algunos sectores (a pesar de que el salario en la industria maquiladora es sólo alrededor de 1.5 salarios mínimos), este impulso no se ha difundido al resto de la economía.

Y en efecto, el crecimiento de la economía y, más aún, el crecimiento per cápita son muy bajos. En promedio, en los años de Peña Nieto el crecimiento del PIв fue menor a $3 \%$, mientras que el crecimiento per cápita fue de sólo $1.3 \%$. En contraste, hemos incluido los datos de China e India (véase gráfica 2).

Una de las principales razones por las cuales la economía mexicana crece poco es la baja inversión. Si comparamos a México con dos países que crecen aceleradamente vemos la gran diferencia. Mientras que en México la inversión estuvo entre el 20 y el $25 \%$ del PIB, en India y en China se encuentran entre el 35 y el $50 \%$ (véase gráfica 3). Esto nos obliga a buscar la explicación en las razones por las cuales se invierte poco en México.

De la crisis de la deuda al estancamiento económico, México, El Colegio de México, 2009; Robert Blecker y Gerardo Esquivel, "NAFTA, trade and development”, California, Universidad de San Diego, 2010; Gerardo Esquivel, "De la inestabilidad macroeconómica al estancamiento estabilizador: el papel del diseño y la conducción de la política económica”, en Nora Lustig, Los grandes problemas de México. IX Crecimiento Económico y Equidad, México, El Colegio de México, 2010; H. Guillén Romo, "México, ejemplo de las políticas anti-desarrollo del Consenso de Washington", Estudos Avançados, 26, núm. 75 (2012); J. Ros, "Las trampas del lento crecimiento y tres reformas recientes", en Rolando Cordera (coord.), Más allá de la crisis. El reclamo del desarrollo, México, FCE, 2015; J.C. Moreno Brid, "Cambio estructural para el crecimiento económico: grandes pendientes de la economía mexicana”, en Rolando Cordera (coord.), Más allá de la crisis. El reclamo del desarrollo, México, FCE, 2015. 
GRÁFICA 2

Crecimiento del PIB ( $\%$ anual)

20

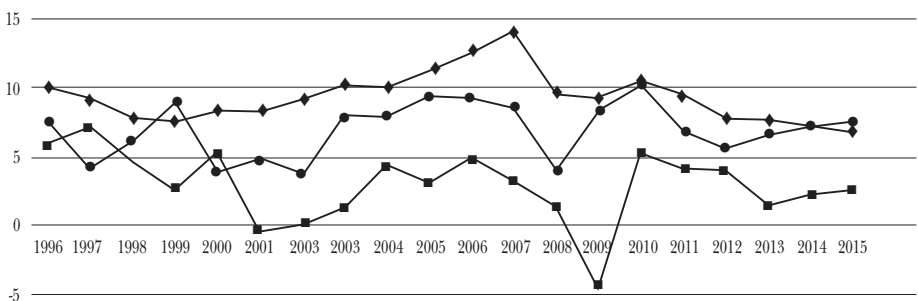
$-10$

$\multimap$ MÉXICO $\bullet$ CHINA $\multimap$ INDIA

Fuente: World Bank Databank.

Gráfica 3

Formación bruta de capital fijo

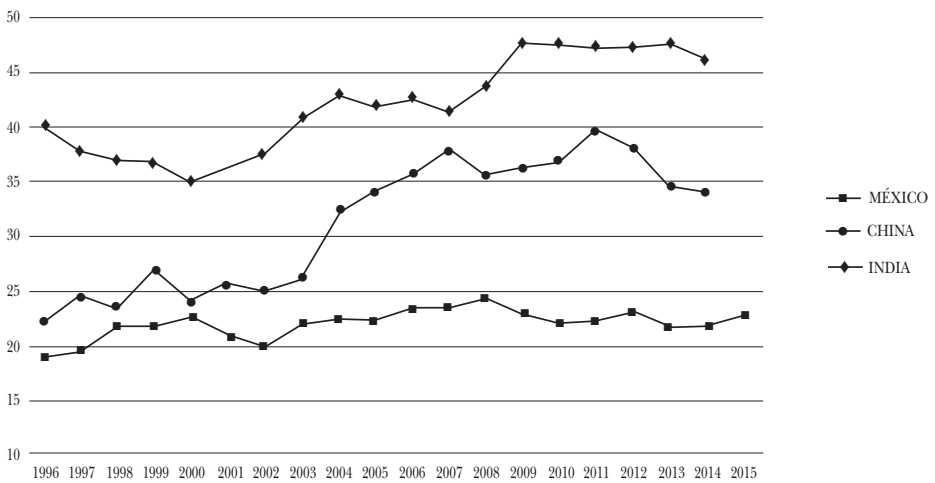

Fuente: World Bank Databank.

Mientras que las exportaciones están vinculadas a la estructura productiva de Estados Unidos y crecen en función de su demanda, el mercado doméstico tiene otra dinámica determinada por la baja inversión estatal y privada y por el bajo consumo. La baja inversión estatal resulta, en parte, de una 
reducida recaudación del gobierno. La baja inversión privada es resultado de los escasos estímulos: carencia de una política industrial, que fue central en los países que lograron industrializarse tardíamente. Además, faltan créditos, tanto de la banca pública de desarrollo, como de la banca comercial. Por otra parte, el nivel de consumo es exiguo debido a los bajos salarios y por el hecho de que, como el sistema de protección social mexicano es muy deficiente, la población tiene que gastar y ahorrar para sobrellevar los gastos en educación, salud, apoyo a los adultos sin pensión, y tienen entonces menos recursos para consumir. La inversión también se ve desestimulada por la desigualdad, porque la riqueza se concentra en sectores sociales que gastan en productos suntuarios importados y que invierten sus ahorros en el exterior, mientras que las mayorías recurren a mercados locales de productos básicos, poco elaborados. Son las clases medias las que dinamizan las economías al inducir la inversión en bienes públicos ${ }^{9}$ y en productos con mayor complejidad, que pueden dar lugar a la elevación del nivel tecnológico de la estructura económica local. ${ }^{10}$ Varios estudios socioeconómicos plantean, además, que la polarización de una sociedad entre pobres y ricos implica inseguridad social y política que desestimula la inversión. ${ }^{11}$ Todo ello lo expondremos enseguida.

La estructura productiva: una economía desarticulada y cadenas productivas fragmentadas

La explicación del lento crecimiento del país es multivariada, pero proviene en esencia del hecho de que donde fluye la mayoría de las inversiones es una plataforma de exporta-

${ }^{9}$ William Easterly, "The Middle Class Consensus and Economic Development”, Journal of Economic Growth, 6, núm. 4 (2001).

${ }^{10}$ Abhijit Banerjee y Esther Duflo, "What is middle class around the world?”, Journal of Economic Perspective 22, núm. 2 (2008).

${ }^{11}$ D. Rodrik, “¿Por qué hay tanta inseguridad económica en América Latina?", Revista de la CEPAL, núm. 73 (2001). 
ción que prácticamente sólo incorpora salarios al proceso manufacturero. Esto se demuestra si comparamos los datos de los intercambios externos con los del crecimiento del PIB. Aparece claramente que mientras el crecimiento de las exportaciones ha llegado a ser muy considerable en 2012, 2014 y 2015, y las importaciones han crecido a la par o más, el PIB ha crecido mucho menos.

\section{GrÁFICA 4}

Crecimiento de los intercambios externos y de la economía en general

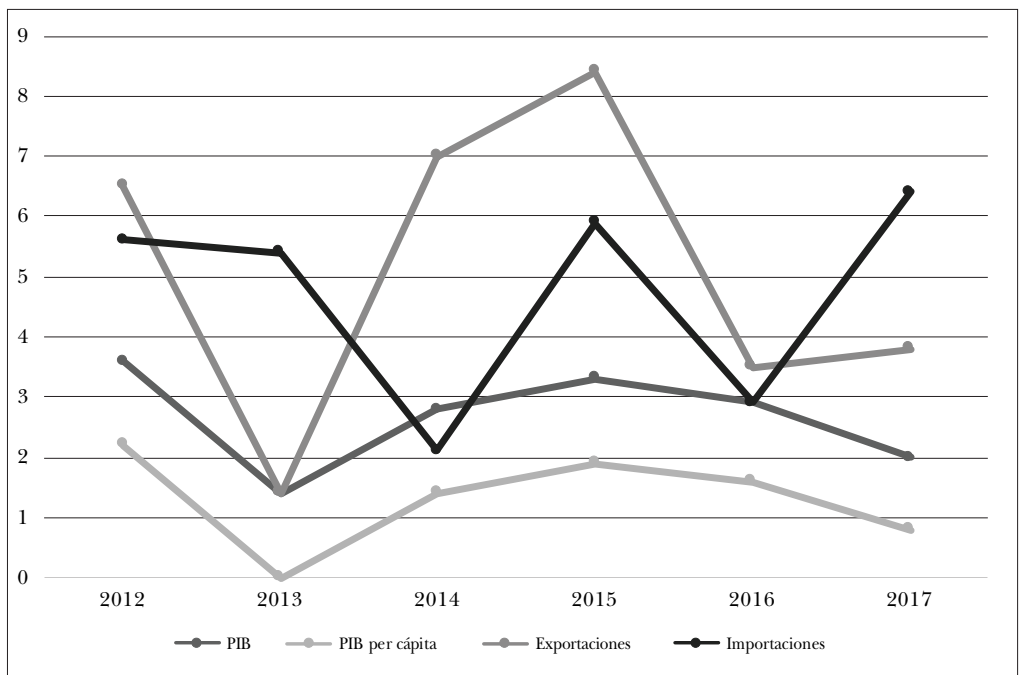

Fuente: World Bank Databank.

La explicación puede parecer tautológica, aunque no lo sea. Las exportaciones están más vinculadas a las importaciones que al resto de la economía, son en cierta manera un enclave. México importa componentes, o produce piezas que se exportan luego de un proceso y que regresan para ser ensam- 
bladas en el país. Dussel ${ }^{12}$ calculó que más del $70 \%$ de las importaciones mexicanas son temporales (que están exentas de aranceles) y que son reexportadas. A partir de 2003 se permite la importación, sin pago de aranceles, de materias primas si se utilizan para exportaciones dirigidas a países distintos de Canadá y Estados Unidos. Es por ello que la razón entre el crecimiento de las exportaciones y el valor agregado ha caído constantemente desde que se implementó el modelo exportador, del 0.9 en 1970 y 1981, al 0.1 en $2000 .{ }^{13}$ En el mismo sentido, el multiplicador keynesiano de las exportaciones sobre la economía mexicana se ha desplomado, de 3.6 en 1987 a 1.6 en 2007. ${ }^{14}$ De hecho, según este autor, a medida que aumentan las exportaciones se incrementan más que proporcionalmente las importaciones porque, además de las importaciones que requieren las exportaciones, la apertura indiscriminada de la economía conduce al rompimiento de las cadenas productivas y a la desindustrialización.

La economía mexicana se mantiene desarticulada en la medida en que se inserta de manera pasiva al mercado internacional: ${ }^{15}$ son las empresas nacionales y transnacionales las que eligen los sectores a desarrollar y lo hacen en aquellos que les permiten aumentar su competitividad internacional. La inversión, preferentemente en los sectores de mayor densidad de mano de obra, implica un proceso de desestructuración de las cadenas productivas nacionales y la integración en los mercados internacionales con base en los procesos de menor valor agregado. Esta dinámica de las cadenas productivas, que responde a la estrategia global las empresas transnacionales, es poco conducente para que los capitales nacionales

12 Enrique Dussel Peters, "La manufactura en México: condiciones y propuestas en el corto, mediano y largo plazo", en José Luis Calva (coord.), Nueva política de industrialización. Vol. 7 de Análisis Estratégico para el desarrollo, México, Juan Pablos Editor, Consejo Nacional Universitario, 2011.

13 Palma, art. cit.

14 Ibarra, art. cit.

15 Moreno Brid, art. cit., p. 195. 
se integren a ellas, a menos que el Estado los obligue o estimule a ello.

Es bien conocido que, en los años sesenta, los gobiernos de Corea y Taiwán forzaban o estimulaban al capital privado a invertir en ciertos sectores industriales. Cuando consideraba que estos sectores estaban maduros, dejaba de protegerlos para apoyar a otros. Todo mediante un proceso pragmático de "prueba y error", más que mediante un plan preconcebido, pero que logró consolidar cadenas productivas cada vez más sofisticadas hasta lograr hacer de estos dos países economías desarrolladas. ${ }^{16}$

De hecho, a pesar de que México ha desarrollado una amplia industria manufacturera de exportación y de que el porcentaje del PIB que ocupa este sector se ha mantenido prácticamente estable, ha habido una especie de desindustrialización. ${ }^{17}$ La apertura indiscriminada y la conversión de la economía en una plataforma de subcontratación internacional tuvo como resultado que la industria mexicana se concentrara en los procesos con menor valor agregado, al tiempo que se trasladaron al exterior los de mayor valor. En el país subsistieron los procesos con mayor concentración de mano de obra, lo que fue positivo en cuanto a la creación de empleos, pero negativo en lo que respecta a salarios y, sobre todo, en upgrading, pero ha conducido, de hecho, a un proceso de downgrading.

Esto puede verse con datos duros si nos remontamos a los años ochenta, cuando el valor agregado como porcentaje del PIB de la manufactura representaba 22\% del PIB, mientras que en 2018 representó 17\%. Es cierto que otros países

${ }^{16}$ Stephan Haggard, Pathways from the Periphery. The Politics of Growth in the Newly Industrializing Countries, Nueva York, Cornell University Press, 1990.

${ }^{17}$ Hector Guillén Romo, "México: del desarrollo 'hacia adentro' al desarrollo 'hacia fuera'”, en Jose Luis Calva (coord.), Análisis estratégico para el desarrollo, vol. 3, México, Juan Pablos Editor, 2012, pp. 245-283 y Héctor Guillén Romo, "México, ejemplo de las políticas anti-desarrollo del Consenso de Washington”, Estudos Avançados, 26, núm. 75 (2012). 
de América Latina han sufrido una desindustrialización aun mayor debido a la reprimarización de sus economías, resultado de la enfermedad holandesa. ${ }^{18}$ En contraste, también es cierto que las verdaderas potencias manufactureras rebasan con mucho los porcentajes mexicanos: en China y en Corea la manufactura representaba, en 2018, el $29 \%$ y el $27 \%$ del PIB, respectivamente. No obstante, estos datos no miden el grado tecnológico de las manufacturas, que es mucho mayor en Corea y con toda probabilidad también en China. Igualmente interesante es el contraste entre Corea y México en el largo plazo, puesto que mientras que en 1960 Corea era un país agrícola, con apenas $10 \%$ de valor agregado de la industria manufacturera, alcanzó a México hacia mediados de los años setenta, para rebasarlo en 1988 y mantenerse cerca del $30 \%$ desde entonces. Mientras que México desciende en los ochenta para ubicarse sin cambios desde mediados de los noventa.

En las dos gráficas siguientes es posible evaluar al gobierno anterior: mientras que en la gráfica 6 podemos ver que la manufactura deja de caer, como lo venía haciendo de 2000 a 2009, crece muy poco en los siguientes años, lo cual prueba que tanto el gobierno de Calderón, como el de Peña hicieron poco para estimular una mayor integración doméstica. En la gráfica 7 vemos que la productividad total de la economía aumentó muy poco, apenas $3 \%$ en 6 años, mientras que la productividad de la industria prácticamente se desplomó, al bajar de un índice de 100 a 90 (véase gráfica 7).

${ }^{18}$ L. C. Bresser Pereira y Paulo Gala, "Macroeconomía estructuralista del desarrollo: ¿un segundo momento del estructuralismo latinoamericano?", en Jose Luis Calva (coord.), Análisis Estratégico para el Desarrollo, vol. 4 (2012). 
GRÁFICA 5

Valor agregado de la industria manufacturera (\% del PIB)

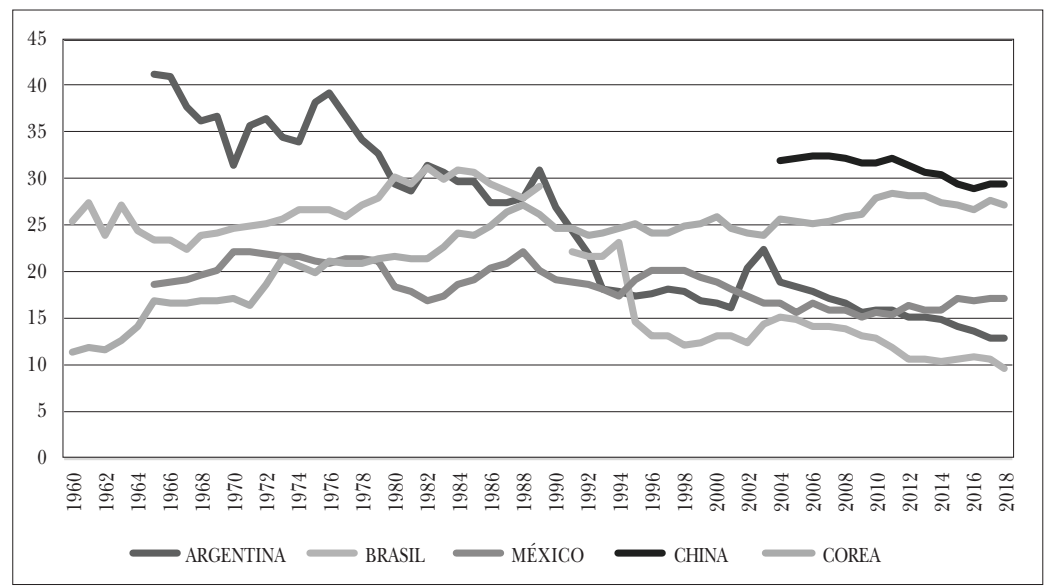

Fuente: World Bank Databank.

\section{GrÁFICA 6}

México: valor agregado de la industria manufacturera, 2000-2018 (\% del PIB)

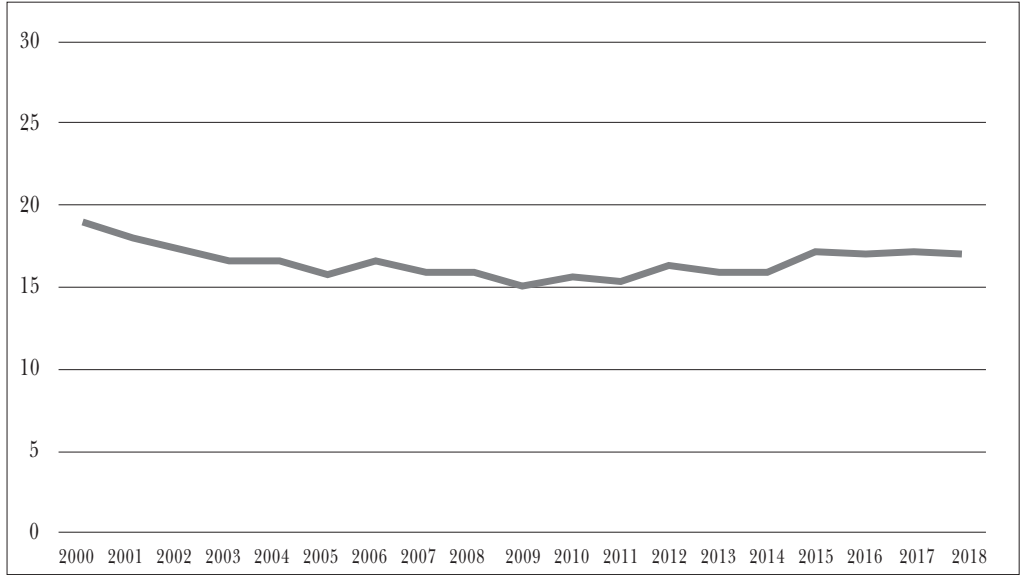

Fuente: World Bank Databank. 


\section{Gráfica 7}

Índice de productividad laboral de la economía mexicana: 2006-2017

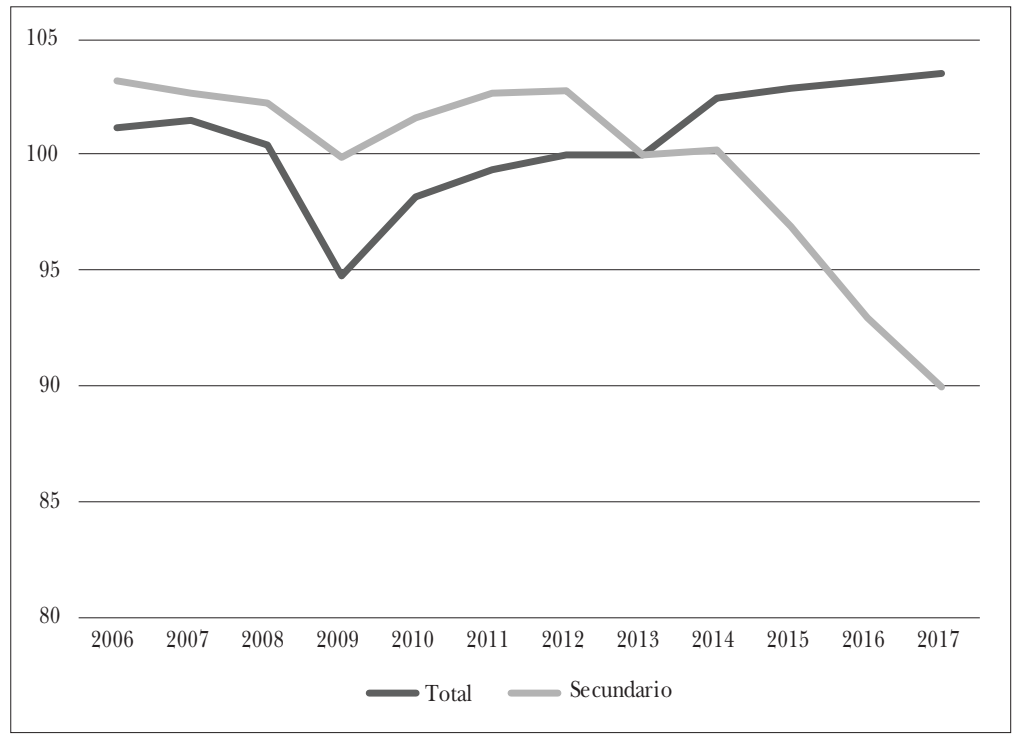

Fuente: elaboración propia con base en Consejo Nacional de Evaluación de la Política de Desarrollo Social, Coneval, Diagnóstico de productividad y análisis de los avances del Programa para Democratizar la Productividad 2013-2018, México, Coneval, 2018.

No obstante, hay que aclarar que los bajos niveles de productividad general de la economía no significan que no haya sectores muy productivos, como los de la industria automotriz, siderúrgica, entre otros. Es en estas ramas más productivas, dominadas por las empresas transnacionales, que se aplican las tecnologías de punta, incluso más avanzadas que las de sus países de origen, en la medida en que son empresas más nuevas. De hecho, a esto se refiere el perspicaz análisis de Palma, ${ }^{19}$ quien escribe que estas empresas aprovechan me-

${ }^{19}$ Palma, art. cit. 
nos los salarios que la brecha entre éstos y la productividad; es esta brecha la que permite la acumulación de ganancias de una de las formas de capital que se instala en México, la otra es la clásica maquiladora que sólo se beneficia de los bajos salarios.

\section{La inversión pública}

Una de las preocupaciones mayores de los gobiernos mexicanos del periodo neoliberal ha sido mantener el gasto del gobierno bajo control, aun a costa de sacrificar el crecimiento y, en épocas de crisis, profundizándola, al actuar de manera procíclica. Durante la mayor parte de la última década el gobierno ha mostrado un saldo fiscal positivo. Incluso en la crisis global de 2008-2009, el déficit presupuestal del gobierno de México no aumentó; en contraste, los gobiernos de Brasil, Argentina e incluso el muy liberal Chile, aumentaron su gasto y déficit de manera muy considerable para intentar contrarrestar los efectos de la crisis. El gobierno de Peña Nieto siguió con esta política: el saldo fiscal primario fue de $0.2 \%$ del PIB en 2016, $1.2 \%$ en 2017 y $0.6 \%$ en 2018 , bien que, durante la segunda mitad del año electoral de 2018 incurrió en un déficit de $2.9 \% .^{20}$

De hecho, desde los años noventa, todos los gobiernos mexicanos han aplicado una política ultrarrestrictiva de gasto, cuyo objetivo primordial ha sido mantener la inflación bajo control. A esto contribuye el Banco de México, institución que tiene como misión principal la estabilidad de precios cuando, por ejemplo, otros bancos centrales también vigilan la tasa de empleo; entre otros, la Fed estadounidense. Ello no sólo conduce a un bajo gasto público y a una política monetaria restric-

${ }^{20}$ Comisión Económica para América Latina y el Caribe, CEPAL, CEPAlstat, Bases de Datos y Publicaciones Estadísticas Comisión Económica para América Latina y el Caribe, https://estadisticas.cepal.org/cepals tat/Portada.html?idioma=spanish 
tiva de intereses elevados, sino a una acción procíclica del gobierno: se gasta cuando la economía está creciendo y se deja de gastar cuando su acción es más necesaria, es decir, en las crisis. ${ }^{21}$

A pesar de que al inicio del sexenio se dijo que se iba a revertir la tendencia de las administraciones precedentes, y que el gobierno iba a aumentar su gasto de inversión, no se cumplieron las expectativas. De hecho, se redujo la inversión de manera considerable en la segunda mitad del periodo. A seis meses de haber entrado en funciones, el gobierno anunció un gran programa de inversiones en infraestructura y, en abril de 2014, siguió otro plan, aún más grandilocuente, el Plan Nacional de Infraestructura, que debía invertir 7.7 billones de pesos, la mitad en el sector energético. Muchos proyectos no vieron la luz, dado que este plan incluía inversiones público-privadas que nunca se concretaron. De todas maneras, el $36 \%$ estatal previsto era considerable. ${ }^{22}$ No obstante, los pocos recursos del gobierno por la baja recaudación estructural del Estado mexicano, la baja de la producción y del precio del petróleo, hicieron insostenible el plan. ${ }^{23}$

Desde el inicio del sexenio, el tren rápido entre la Ciudad de México y Querétaro abortó por el famoso escándalo (así denominado) de la "Casa Blanca” en el que, además de la esposa del presidente, estuvo implicado el ganador del contrato junto con una compañía China. De esta manera, “...la política de inversión pública de este periodo adoptó una postura ultrarrestrictiva que restó dinamismo al crecimiento tanto por el lado de la demanda agregada como el de la oferta, al restringir la formación de capital público e infraestructura". ${ }^{24}$ De hecho, el gasto público en bienes y servicios (consumo más inversión públicos) pasó de crecer a una tasa anual de 3.2\%

${ }^{21}$ Esquivel, art. cit.

22 Ros, art. cit., pp. 167-168.

${ }^{23}$ Víctor Soria Murillo, Saldos perversos de la política neoliberal en México, UAM-Colofón, 2017, p. 357

${ }^{24}$ J. Ros, "La economía mexicana en 2016: tendencias y perspectivas", Revista de Economía Mexicana, Anuario UNAM, núm. 2, 2017, p. 8. 
entre 2002 y 2007 a decrecer a $-0.2 \%$ anualmente de 2009 a 2016, cayendo del $4.2 \%$ en 2002-2007 a 3.2\% del PIB al inicio del sexenio; la inversión pública sufrió un colapso acumulado sin precedente, de $35 \%$, y su proporción con respecto al PIB cayó de 5.9 a $3.1 \% .{ }^{25}$ En la gráfica 7 podemos ver que, a pesar de que de 2014 a 2015 aumentaron los ingresos por impuestos del gobierno, su consumo no aumentó. Esto demuestra que el gobierno ejerció una política hiperrestrictiva, a pesar de que tenía más recursos, decidió no gastarlos.

\section{Gráfica 8}

Impuestos y consumo del gobierno (\% del PIB)

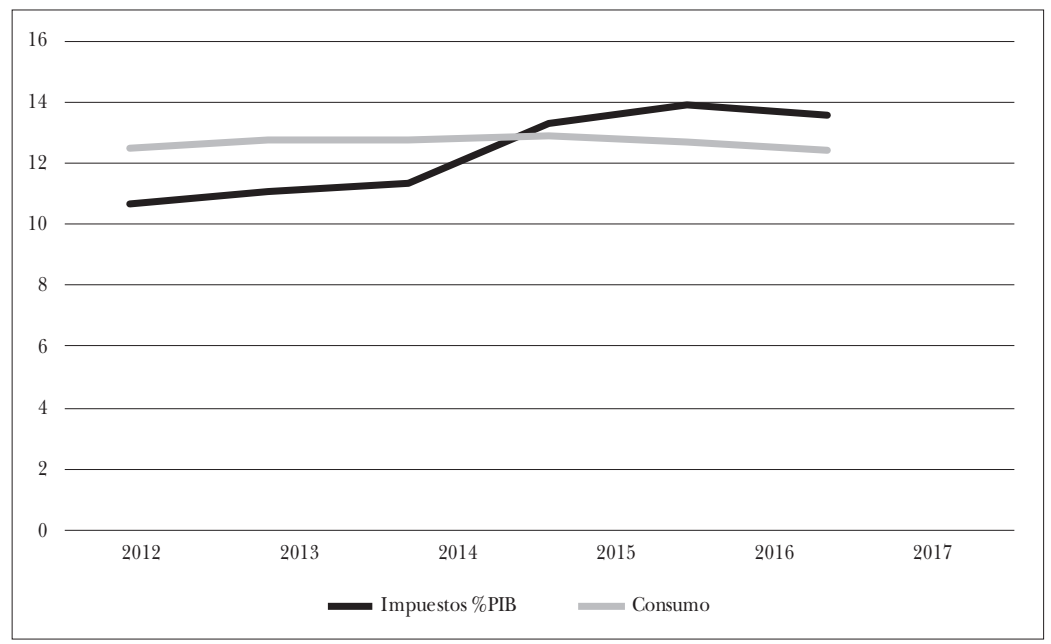

Fuente: datos para la elaboración del Bertelsmann Transformation Index, BTI2018 Transformation Index (World Bank), https://www.bti-proje ct.org/en/data/ (consulta de agosto de 2019).

Vale la pena comparar el consumo del gobierno mexicano con el de varios países que han logrado o intentado crecer rápidamente.

${ }^{25}$ Loc. cit. 
GrÁFICA 9

Consumo del gobierno en México, China, Brasil y Corea

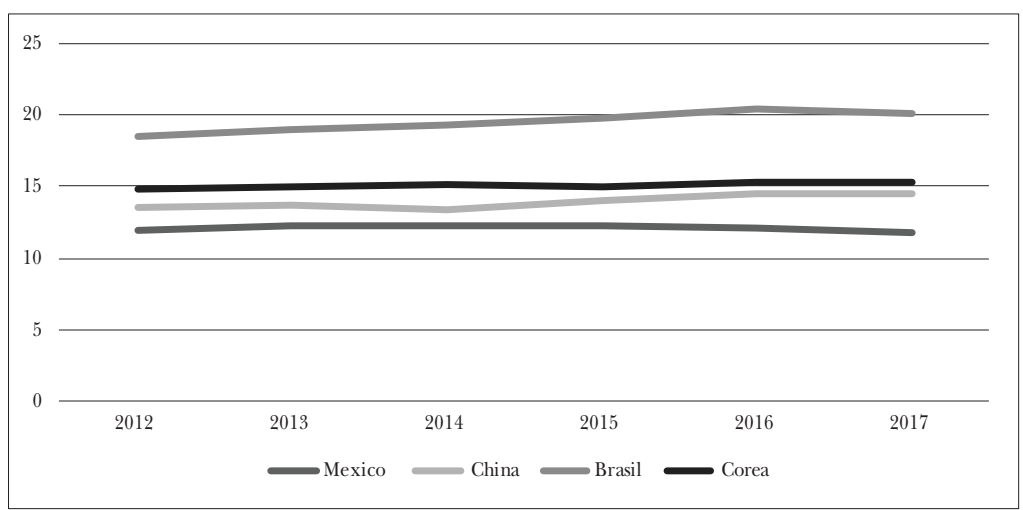

Fuente: datos para la elaboración del Bertelsmann Transformation Index, BTI2018 Transformation Index (World Bank), https://www.bti-pro ject.org/en/data/ (consulta de agosto de 2019).

En gran medida, el bajo gasto del Estado mexicano se debe a su reducida capacidad fiscal y al bajo nivel de contribuciones que se hacen al sistema de seguridad social, ya que México es uno de los países de América Latina que ejerce la menor presión fiscal y recaudación de contribuciones sociales. En la raíz de esta baja tributación se encuentra la estrategia de sustituir la carencia de estímulos directos a ciertos sectores productivos que implicaría tener una política industrial activa, por una ausencia de política industrial que elimine cualquier tipo de restricción al capital para inducirlo a invertir. En la gráfica 10 podemos comparar el Estado mexicano con otros países del continente.

Los datos del sexenio de Peña Nieto indican que mejoró la recaudación fiscal con lo que se denominó una reforma, pero que en realidad fue más bien una miscelánea fiscal en la medida en que sólo se ajustaron los impuestos existentes, sin crear otros o modificar significativamente el sistema. ${ }^{26}$ Se aumentó

${ }^{26}$ Soria, op. cit. p. 126. 
el ISR a las personas físicas, a un máximo de $35 \%$, y se descartaron exenciones y deducciones del ISR personal y empresarial. Además, se introdujo un impuesto del $10 \%$ a las ganancias de capital y se eliminó el régimen de consolidación fiscal y el IETU. Todo ello afectó principalmente a las clases medias. ${ }^{27}$

GrÁFICA 10

Ingresos del Estado; impuestos y contribuciones (\% del PIB)

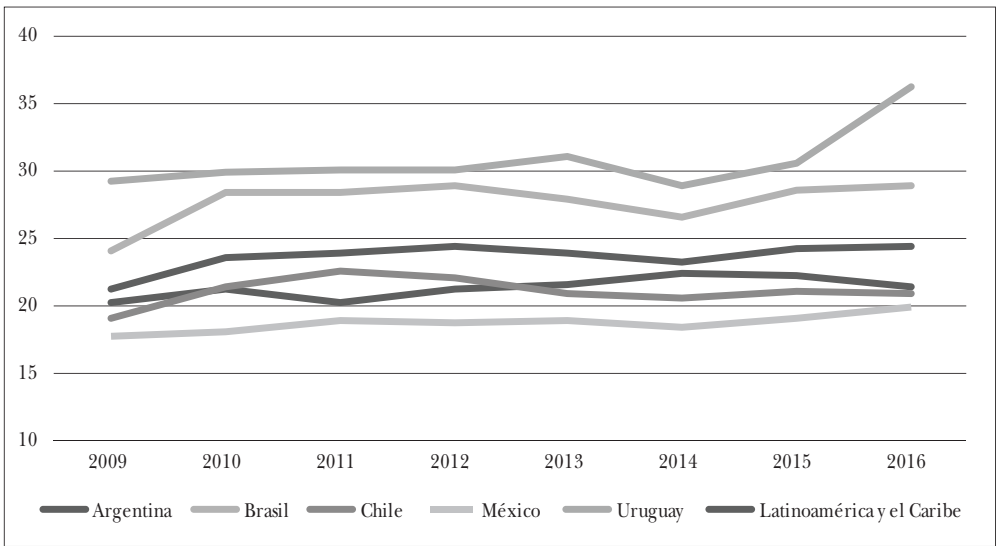

Fuente: Comisión Económica para América Latina y el Caribe, CEPAL, CEPALSTAT.

Pero estas modificaciones no lograron siquiera compensar la caída de los recursos que provenían de Pemex. Mientras que la miscelánea fiscal logró incrementar la recaudación en $3.5 \%$, para llevarla de $9.1 \%$ a $13.1 \%$ del PIB de 2013 a 2017, la caída de los ingresos petroleros hizo descender los ingresos fiscales en $4.5 \%$ del PIB, al pasar de $8.3 \%$ a $3.8 \%$ en el mismo periodo. ${ }^{28}$ La caída de los ingresos petroleros provino básica-

${ }^{27}$ Ibid., p. 127.

${ }^{28}$ Instituto Belisario Domínguez, "La reforma hacendaria a cuatro años de su implementación. Resultados y propuestas", Notas estratégicas, núm. 27 (julio de 2018). 
mente de la baja en la producción, exportación y precio del petróleo. A esto habría que agregar lo que se perdía por los subsidios que se otorgaron durante muchos años a las gasolinas, que son importadas, junto con el gas y otros productos petroquímicos.

La penuria de recursos llevó a un muy notable endeudamiento del sector público desde el sexenio de Felipe Calderón. En el cuadro del anexo, podemos ver que el endeudamiento público ha pasado de $42 \%$ a $52 \%$ del PIB de 2012 a 2017. A pesar de que este nivel de deuda no se considera excesivo para un país en desarrollo, sí ha tenido como consecuencia que haya aumentado el costo financiero, lo que ha reducido aún más la capacidad de ejercer gasto público. ${ }^{29}$ Por otra parte, la deuda total del país pasó de 350000 millones a 455000 millones de dólares, lo que implica una carga anual por intereses de 62000 millones de dólares. Aunque la mayor parte de la deuda es privada, el responsable, en última instancia, es el gobierno, lo que lo obliga a acumular grandes cantidades de reservas de divisas. Esto también es necesario por la volatilidad de las inversiones en portafolio, que pueden muy rápidamente dejar el país, así como el efecto de sobrevaluación del peso si no se "esterilizan”. En ciertos momentos, algunos países han establecido limitaciones a los capitales de portafolio, como un impuesto a su salida antes de cierto tiempo (por ejemplo, el encaje que aplicó el gobierno chileno en los años noventa). En ausencia de estas medidas, la única solución es la acumulación de reservas que pueden hacer frente a una huida repentina de capitales.

Esta problemática situación de las finanzas públicas obligó a la reforma energética. Aunque es posible que uno de los motivos de esta reforma era ideológico, ya que éste era el último sector económico de importancia en manos del Estado, algo que para el pensamiento liberal era una irregularidad, la decisión se tomó por razones pragmáticas. La creciente dificultad que tenía Pemex para aportar los recursos necesarios

${ }^{29}$ Soria, op. cit. p. 77. 
al gobierno, su creciente debilidad financiera, convencieron al gobierno de la necesidad de abrir un mercado cuyo monopolio le había dado grandes beneficios en el pasado: de 2000 a 2013, 40\% de los recursos del gobierno provinieron de Pemex. ${ }^{30}$ Mientras esta empresa pudo ofrecerle al gobierno un complemento tal de sus recursos fiscales, hubiera sido suicida abrir el mercado. Ello además le permitía mantener el credo liberal de cobrar pocos impuestos. Es un lugar común que Pemex se utilizaba como caja chica del gobierno. Los impuestos que se le cobraban ascendieron a $114.9 \%$ de sus utilidades antes de impuestos, de 2005 a 2014, una situación claramente inviable que llevó a la baja de la producción y al descuido de las refinerías que producen a menos de $30 \%$ de su capacidad. También condujo a su endeudamiento, convirtiéndose en una de las empresas petroleras más endeudadas del mundo, con una deuda de alrededor de 105000 millones de dólares. ${ }^{31}$

El gobierno de Peña se vio obligado a modificar la relación fiscal del Estado con Pemex, aunque ello no significara "...que la carga tributaria de Pemex y los ingresos que recibirá el Estado se modifiquen de forma significativa en el corto plazo. De hecho, las estimaciones realizadas bajo distintos supuestos apuntan a que la porción que el Estado obtendrá de los ingresos por las actividades de exploración y extracción de hidrocarburos oscilarán en el $63.5 \%$ en 2016 y se reducirá de forma gradual para 2022 hasta alrededor de $60.1 \%$; cifras similares al $63.5 \%$ registrado en 2014 y al $65.0 \%$ del promedio de 2005-2014". ${ }^{32}$ Es de notar que el gobierno de López Obrador redujo aun más los impuestos a

${ }^{30}$ José Luis Clavellina Miller y Víctor Ortega Olvera, "Reforma energética y nuevo régimen fiscal del sector de hidrocarburos", Cuaderno de investigación, México, Senado de la República, Instituto Belisario Dominguez, 2015, p. 5.

${ }^{31}$ Loc. cit.

${ }^{32}$ Loc. cit. 
Pemex, de 65 a $54 \%$ del derecho a la utilidad compartida, ${ }^{33}$ lo cual todavía es elevado.

La promesa de la reforma energética era que el capital privado dinamizaría un sector que el Estado había expoliado. Se argumentaba que Pemex no tenía recursos para seguir invirtiendo en exploración y en explotación y que, además, la mayoría de los pozos de petróleo en tierra o aguas someras se estaban agotando, y que lo que restaba ahora era explorar y explotar pozos en aguas profundas, lo cual era muy costoso, riesgoso y complejo para la empresa mexicana. A diferencia de Petrobras, que invirtió en los años noventa y 2000 en sus capacidades tecnológicas y se convirtió en uno de los países de punta en la tecnología de explotación de aguas profundas para las enormes reservas de presal de la costa de Río de Janeiro, Pemex había abandonado todo intento de mejora tecnológica (upgrading).

Se pensaba, por una parte, que acceder a que Pemex se asociara con firmas privadas le permitiría volverse una empresa viable y, por la otra, que el pago de derechos (royalties) e impuestos que se cobraría a las empresas petroleras, compensarían, por lo menos en parte, lo que Pemex por sí sola ya no podía seguir aportando al gobierno. Además, las inversiones en energía tendrían un efecto multiplicador sobre la economía en general. No obstante, por diversas razones, entre ellas la reducción de la demanda y del precio del petróleo, la promesa de una creciente inversión privada en la industria tampoco se concretó. Además, la nueva "Ley de Pemex", de agosto de 2014, no reforzaba las posibilidades de la empresa frente a la que sería una creciente competencia, al contrario, se dejaba a Pemex en una situación muy desventajosa porque "...la futura competitividad de Pemex no sólo se verá afectada por la distribución de asignaciones

33 Karen García, "Bajan carga fiscal de Pemex y aporte a ingresos públicos”, El Economista, 22 de julio de 2019, https:/ /www.eleconomista. com.mx / empresas / Bajan-carga-fiscal-de-Pemex-y-aporte-a-ingresos-pu blicos-20190723-0010.html 
al sector privado en las Rondas de Inversión (Rondas de Privatización), sino por la continuidad del secuestro de sus utilidades por medio de impuestos y derechos que lo dejan sin posibilidades de modernización y desarrollo". ${ }^{34}$

\section{La inversión privada}

El crecimiento de la economía no es sólo resultado de la inversión del Estado, sino del capital privado, que depende de las condiciones mismas del mercado y de la estructura económica, de los incentivos del gobierno y, finalmente, del consumo. Por eso, es necesario explicar por qué la inversión privada mexicana es tan reducida. En parte se explica por la escasa inversión y consumo públicos que mencionamos en líneas previas. No obstante, también depende de las oportunidades de acumulación de capital en función de la estructura productiva, del grado de oligopolización y monopolización de ésta, tanto en el mercado interno, como en el de exportación. Además, responde a los incentivos del gobierno para que aumente su oferta y las posibilidades mismas de exportación. Y, finalmente, obedece a la dinámica y estructura del consumo.

La falta de una política industrial y de apoyo financiero

Como ya lo hemos discutido, el modelo que ha seguido el país gira en torno de la inversión extranjera en la plataforma de exportación, de la que está prácticamente ausente el capital nacional. Mientras que en la industria maquiladora la integración nacional es prácticamente nula, en otras, como la automotriz, donde hay mayor integración doméstica, se han instalado proveedoras extranjeras dado que las abastecedo-

${ }^{34}$ Soria, op. cit., p. 278. 
ras nacionales son prácticamente inexistentes. ${ }^{35}$ Esto, en gran medida se debe a que para el capital privado es muy difícil integrarse a las cadenas de valor controladas por el capital extranjero sin algún tipo de ayuda del Estado. Y, en efecto, según Moreno Brid “... la falta de una política industrial [...] explica por qué el giro en la agenda de desarrollo y las reformas de mercado y el auge exportador no lograron tasas de expansión persistentes del PIB de cuando menos $5 \%$ anual". ${ }^{36}$

En contraste con el gobierno mexicano de la época del ISI, y con la acción de los gobiernos de Japón, Corea y Taiwán y del actual gobierno chino, que estimulaban la generación de cadenas productivas, empezando por los bienes de consumo no duraderos, pasando a los bienes de consumo duraderos, los bienes intermedios y, finalmente, los bienes de capital, así como la inversión en ciencia y tecnología, para incrementar su valor agregado, a partir de los noventa el gobierno mexicano dejó a los productores libertad total de escoger dónde invertir y dejó de proteger y dirigir las empresas. Lo único que puede remediar esta situación es una política industrial que "...genere los eslabonamientos fuertes con los proveedores nacionales, de modo que, al aumentar su contenido local, se fortalezca su capacidad de impulso al resto de la economía". ${ }^{37}$

A pesar de que en el Plan Nacional de Desarrollo del gobierno de Peña Nieto se contemplaba que el gobierno iba a “...resolver las distorsiones del mercado [como] los monopolios u oligopolios, mercados incompletos, información asimétrica y de coordinación de los agentes [...], la colaboración entre el sector privado y el gobierno para desarrollar los sectores con mayor impacto en el crecimiento económico $[\ldots]$, implementar acciones e instrumentos específicos como la promoción del capital humano y financiamiento y

35 T. Hoshino, Red de proveeduría de la industria automotriz en México: ¿̨es posible la incorporación de las empresas mexicanas?, Guadalajara, Universidad de Guadalajara, 2018.

36 Moreno Brid, art. cit., p. 62.

37 Loc. cit., p. 195. 
en coordinar, focalizar y priorizar las acciones conjuntas entre el sector privado y los distintos órdenes de gobierno", ${ }^{38}$ todo quedó en palabras.

En lo que se refiere a la banca de desarrollo, el Estado mexicano ha mantenido bajo su control seis bancos, entre los que Nacional Financiera (Nafin) y Bancomext son los principales. El primero, creado en 1934, fue el banco mexicano más importante durante la ISI, aunque en lo que respecta a los activos, ambos se cuentan entre los más grandes de América Latina, no pueden considerarse como bancos de desarrollo debido a que “...están regulados y supervisados como los bancos comerciales y están obligados por ley a preservar el valor real de su capital". ${ }^{39}$ Además, sus funciones están muy restringidas: Nafin redujo su papel desde la crisis de 1982 e intensificó su retirada con la apertura comercial y financiera de los años noventa. Las operaciones de crédito para la inversión productiva de este banco se redujeron en $70 \%$ entre 1996 y 2004, por lo que su función principal se volvió garantizar los préstamos ofrecidos por bancos comerciales a pequeñas y medianas empresas. Este banco se ha centrado en el factoraje ("factoring"): pagar por adelantado las facturas adeudadas por proveedores o clientes a pequeñas y medianas empresas. ${ }^{40}$ De hecho, esta función se ha convertido en una de las más relevantes, “...representa un mercado importante, con una facturación total de la industria estimada en casi 11 mil millones de euros en 2007 (casi el 2 por ciento del PIB)". ${ }^{41}$

Durante el sexenio de Peña Nieto se dieron a la banca de desarrollo, Nafinsa, Bancomext y Banobras, más facultades

38 Secretaría de Economía (2013), citada por loc. cit., p. 62.

39 A. de la Torre, A. Ize, y S. L. Schmukler, Financial development in Latin America and the Caribbean. The Road Ahead, Washington, DC, IBRD, World Bank, 2012, p. 157.

${ }^{40}$ Irma Manrique Campos, "Banca de desarrollo en México: un futuro necesario", en J. L. Calva, Agenda para el Desarrollo, Vol. 6: Financiamiento del crecimiento económico, México, Porrúa-unam, 2007, pp. 111-113.

41 Torre, Ize, Schmukler, op. cit., p. 49. 
para funcionar como banca de primer piso y se aumentaron sus recursos. La reforma financiera de 2014 efectivamente otorgó a la banca de desarrollo una mayor capacidad para financiar a las PyMEs; en 2016, 45\% de la cartera de Nacional Financiera y $71 \%$ de la del Banco Nacional de Comercio Exterior se orientó de esta manera. ${ }^{42}$ No obstante, la cartera total y su alcance son limitados ya que, a pesar de que subió de $1.6 \%$ en 2007, sólo representa 3\% del PIB, y la mitad de esa cifra se canaliza a créditos comerciales. ${ }^{43}$ Estos datos adquieren su verdadera dimensión si tomamos en cuenta que, en 2016, el Banco de la Nación Argentina manejó 9.7\% del PIB en activos, mientras que el BNDES de Brasil manejó el 15\%.

\section{GRÁFICA 11}

Inversión en Investigación y Desarrollo 1996-2016 (\% del PIB)

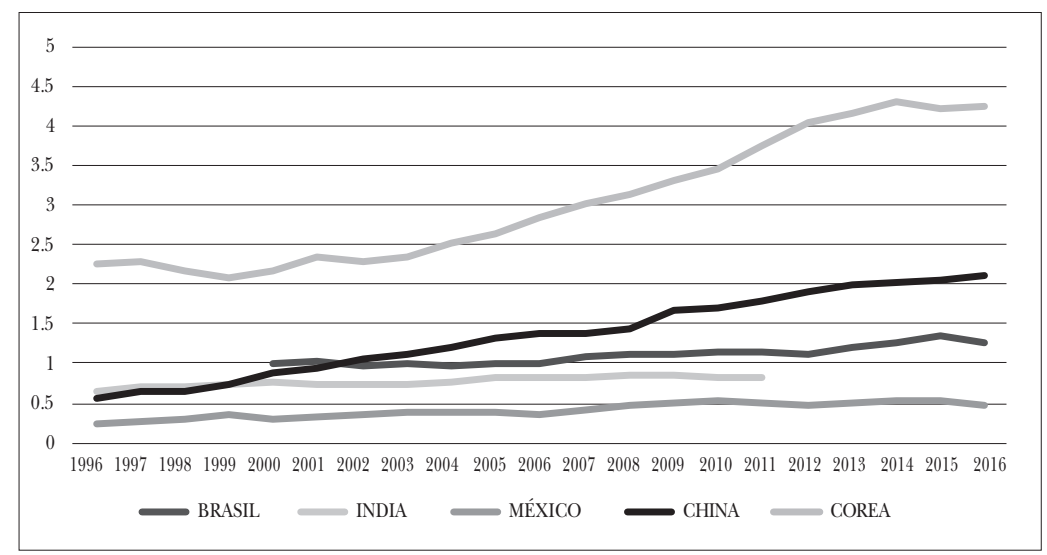

Fuente: World Bank Databank.

${ }^{42}$ R. V. Lecuona, "Inclusión financiera de las pequeñas y medianas empresas en México: el papel de la banca de desarrollo", en Esteban Pérez Caldentey y Daniel Titelman (eds.), La inclusión financiera para la inserción productiva y el papel de la banca de desarrollo, Libros de la CEPAL, núm. 153 (LC/PUB.2018/18-P), Santiago, Comisión Económica para América Latina y el Caribe, 2018, p. 165.

${ }^{43}$ Loc. cit., p. 157. 
Hay que mencionar un último elemento en relación al apoyo del Estado a la inversión privada: los recursos invertidos en investigación y desarrollo. Según los datos del Banco Mundial, mientras que al inicio del sexenio, México gastaba sólo $0.48 \%$ del PIB en este rubro, Brasil gastaba $1.12 \%$, China $1.9 \%$ y Corea $4 \%$. Cuatro años después, México seguía gastando el mismo $0.48 \%$, Brasil había aumentado a $1.26 \%$ (a pesar del liberalismo del gobierno de Temer), China había incrementado a $2.1 \%$ y Corea, a pesar de ser el campeón mundial en este gasto, todavía lo incrementó en $0.22 \%$, para llegar a $4.22 \%$.

\section{Altas tasas de interés y sobrevaluación} de la moneda

A la falta de estímulos a la inversión privada, debemos añadirle los obstáculos a la inversión: las altas tasas de interés y la sobrevaluación del peso. Si bien ambas son favorables para atraer capitales que compensen el desequilibrio en la balanza comercial que genera el modelo de capitalismo mexicano, son un formidable obstáculo para la inversión productiva. Ambas son, también, maneras de controlar la inflación, central para poder mantener bajos los salarios, principal elemento de competitividad de la economía mexicana, además de la cercanía con Estados Unidos y el acuerdo de libre comercio.

La entrada de capitales es vital porque la economía mexicana, como podemos ver en el cuadro anexo, tiene un déficit estructural de cuenta comercial y corriente. Como en prácticamente todos los sexenios anteriores, el año en que termina la cuenta corriente ha sido deficitaria. Cualquier crecimiento de exportaciones y de la demanda interna se refleja en un aumento de importaciones, el multiplicador beneficia al exterior. Y es por ello que las tasas de interés del país deben mantenerse por arriba de las de los países con los que competimos por capitales y tener la inflación bajo control. No obstante, estas tasas de interés elevadas son un obs- 
táculo para los inversionistas nacionales, en especial en un contexto en el cual la banca de desarrollo no presta directamente y cuando la banca comercial prefiere prestar al consumo y obtiene buenas ganancias de los intereses y comisiones; las grandes empresas nacionales e internacionales no recurren a la banca doméstica porque pueden obtener créditos en el mercado internacional de capitales.

Por otra parte, el peso ha estado sobrevaluado desde $1997 .{ }^{44}$ Esto se debe a que la tasa de cambio ha sido utilizada como instrumento para controlar la inflación. Para ello, el gobierno ha mantenido abierta la puerta al capital especulativo $^{45}$ y ha ofrecido bonos que ofrecen altas tasas de interés. Y, en efecto, se ha logrado mantener la inflación bajo control en los últimos 10 años: en 2013 fue de 3.8\%, en 2014, de 4.5\%.

Es bien conocido el planteamiento de Rodrik en el sentido de que la política industrial mas importante es el tipo de cambio. Ya hemos visto como, tanto en Argentina, como en Brasil, una de las fuentes de su desindustrialización fue un tipo de cambio sobrevaluado. ${ }^{46}$ Esto porque una tasa de cambio sobrevaluada estimula las importaciones y castiga la inversión interna. En el caso de Brasil y Argentina, esta situación fue resultado de lo que Bresser Pereira ha llamado la enfermedad holandesa. En el caso mexicano, el peso sobrevaluado resulta de algo que podríamos llamar semienfermedad holandesa, que se debe a la necesidad del gobierno de atraer divisas, lo cual crea un círculo vicioso que se asemeja a la enfermedad holandesa. ${ }^{47}$

${ }^{44}$ Soria, op. cit., p. 247.

45 Jaime Marques Pereira y Miguel Bruno, "Path dependence blocking the emergence of a new type of capitalism favoring redistribution in Brazil: A new view on the possibility of a developmental coalition", Francia, Université d'Amiens (manuscrito), 2015; Soria, op. cit., p. 249.

${ }^{46}$ Loc. cit., y Bresser Pereira y Gala, art. cit.

47 La diferencia entre una "verdadera" enfermedad holandesa y la "semi" enfermedad holandesa mexicana es que la primera implica la entrada masiva de divisas a un país por la exportación de materias primas, que lleva a un círculo vicioso de sobrevaluación de la moneda (a menos 


\section{EL CONSUMO INTERNO}

Una de las causas principales de la falta de inversión (quizá la más importante), además de la falta de inversión pública y de política industrial, las altas tasas de interés y la sobrevaluación del peso, ${ }^{48}$ y la desconexión de las cadenas productivas, es la debilidad de la demanda agregada, sobre la que incide significativamente el consumo de la población. Un país tan grande como el nuestro no puede crecer sólo con base en el mercado externo, éste sólo permite ocupar a una parte de las actividades económicas y de la fuerza de trabajo, por lo que el mercado interno es fundamental. En contraste con el sector que se orienta al mercado externo, el mercado interno ha crecido muy lentamente, como lo demuestran los bajos niveles de creación de empleos y la persistencia de una gran proporción de trabajadores informales.

La debilidad del mercado interno mexicano se debe a los bajos niveles salariales, escasa cobertura del sistema de

que el gobierno esterilice las divisas), al abaratamiento de las importaciones y aumento del precio de las exportaciones, haciendo más difícil la producción industrial y llevando a la desindustrialización de la economía; fenómeno que se produjo en Brasil y Argentina en la última década. En el caso mexicano, la segunda, la entrada de capitales es hacia la inversión en portafolio, más que como resultado de la exportación de commodities, pero el efecto, aunque no tan fuerte, es el mismo, el de la reevaluación de la moneda local.

48 Recordemos cómo a pesar de que en Brasil, tanto el gobierno de Lula da Silva como el de Dilma Rousseff tenían una política industrial muy activa y vertical, se cayó en la desindustrialización debido a la enfermedad holandesa y de la financialización de la economía Renato Raúl Boschi y Carlos Eduardo Santos Pinho, "Desarrollo capitalista, austeridad fiscal y democracia en Brasil”, en Alberto Aziz e Ilán Bizberg, Variedades de capitalismos en crisis, México, El Colegio de México (en prensa). Lo que quiere decir que todas las políticas económcas del gobierno son infructuosas si no existen las condiciones estructurales de la inversión. Por una parte, si no hay compradores, no hay mercado interno, y por la otra, si no hay empresarios, suficientes individuos con espíritu empresarial, no hay inversión; tampoco la hay si los empresarios tienen un espíritu rentista y prefieren invertir en las finanzas que en la economía "real". 
seguridad social, así como la pobreza y la desigualdad. Un indicador de la dinámica del mercado interno es el crecimiento del consumo. En la gráfica 12 podemos ver el muy exiguo crecimiento del consumo de la economía mexicana. Añadimos el crecimiento del consumo en India y en China para ejemplificar el comportamiento de economías muy dinámicas. Aquí también podemos ver cómo en el primer año del sexenio Peña hubo un descenso del consumo y cómo cae de nuevo en los dos últimos años, a la par del descenso de la inversión pública.

GRÁFICA 12

Crecimiento del consumo, 2012-2018

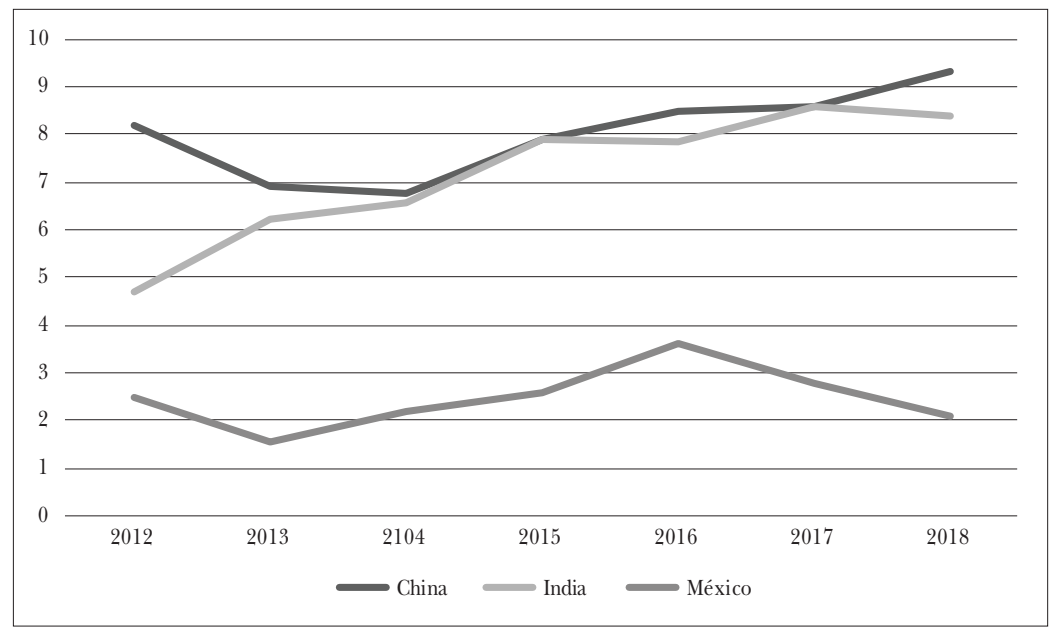

Fuente: World Bank Databank.

Salarios bajos y seguridad social exigua

Los salarios y la cobertura del sistema de seguridad social influyen de manera directa sobre el consumo; lo que la escuela de la regulación llama el régimen de consumo. Hay dos tipos 
de régimen de consumo, el que favorece las ganancias, que tiene como resultado el aumento de la proporción de las ganancias en el PIB, y el que favorece los salarios (incluido el sistema de seguridad social), que aumenta la proporción de los salarios en el PIB. En el fordismo, que existió en Estados Unidos y Europa del fin de la Segunda Guerra Mundial a la crisis del petróleo a mediados de los años setenta, se dio una relación estrecha entre producción y consumo: la producción de masa que aumentaba continuamente con la aplicación de nuevas tecnologías y formas de organización del trabajo requería un consumo igualmente creciente y dinámico, por lo que los empresarios y los Estados redistribuían la riqueza. La manera de distribuir era directa, por la vía de aumentos salariales, e indirecta, por la expansión de las políticas sociales, se trataba de un "wage led growth" que influía en la capacidad de consumo de los sectores populares que contaban con recursos para comprar las manufacturas producidas en masa. A partir de la crisis del fordismo, la imposición del neoliberalismo y la financiarización, se ha producido la acumulación de ganancias a costa de los salarios y de las políticas sociales, un "profit led growth". Éste depende cada vez más de innovaciones tecnológicas y financieras radicales, con lo cual la riqueza se ha concentrado y el consumo se ha visto frenado, lo que ha dado lugar a una tendencia a la estagnación. ${ }^{49}$

El modelo fordista no fue una concesión de los empresarios y del Estado, sino que respondía a la organización de los obreros en sindicatos y su traducción en partidos comunistas y social-demócratas. En el caso mexicano, el sindicalismo fue controlado por el Estado en un sistema corporativista estatal, el cual fue crecientemente sustituido por sindicatos de protección a partir de los años ochenta. Esta economía política

${ }^{49}$ Robert Boyer, “¿Qué significa la creciente variedad de capitalismos contemporáneos para la teoría económica?”, en Alberto Aziz e Ilán Bizberg, Variedades de capitalismo en crisis, México, El Colegio de México (en prensa) y L.C. Bresser Pereira, "Régimen de política económica liberal y cuasi-estagnación en Brasil desde 1990”, en Alberto Aziz e Ilán Bizberg, op. cit. 
de la represión salarial en México es el fundamento competitivo del modelo de subcontratación internacional, debido a que se compite contra los salarios que se pagan en los países vecinos (y lejanos) que pretenden atraer la inversión extranjera. Una ventaja que tiene México frente a otros países de salarios bajos es la cercanía con Estados Unidos, que permite un bajo gasto de transporte y la rapidez con la que llegan los productos al mercado de consumo y de ensamble, algo que se modifica al variar los costos de transporte y el precio del petróleo.

En el caso mexicano, el modelo se ha traducido en bajos niveles salariales y en un sistema de protección social cada vez más enfocado en la asistencia. Hay que tomar en consideración que el salario mínimo ha perdido alrededor de $80 \%$ desde los años ochenta a la actualidad. En la gráfica 13 podemos ver cómo, en un periodo más reciente, los salarios mínimos de México prácticamente no se movieron, mientras que los salarios medios aumentaron muy poco al ser jalados hacia abajo por los mínimos. La razón de la sincronización entre estos dos índices es que los salarios contractuales en México se fijan de acuerdo con los mínimos, debido a que el gobierno fija un tope para su aumento desde los años ochenta. Es también instructiva la comparación con otros países en donde los mínimos han aumentado muy considerablemente. El salario mínimo mexicano es uno de los menores de los países del continente: mientras que en Brasil el mínimo es de 300 dólares, en Uruguay es de 430, en Chile de 396 y en Bolivia de 261, en México es de apenas 132 dólares (según datos de CEPALSTAT para 2017).

Por otra parte, el sistema de seguridad social se ha concentrado progresivamente en otorgar mínimos de sobrevivencia a las poblaciones más pobres, mediante el programa Prospera, mientras que el sistema corporativo es desmantelado. El porcentaje de la población que no tiene seguridad social y tiene que ahorrar o gastar en servicios que en otros países ofrece el Estado, los sindicatos o la propia empresa es enorme en nuestro país, ya que el $57 \%$ no tiene acceso a pensiones y 
el $16 \%$ no está cubierto por los servicios de salud.$^{50}$ No es una sorpresa que con ese nivel de salarios y baja cobertura de la seguridad social, los niveles de consumo sean tan reducidos.

\section{GRÁFICA 13}

Aumento de los salarios mínimos y medios, 2000-2015 (\%)

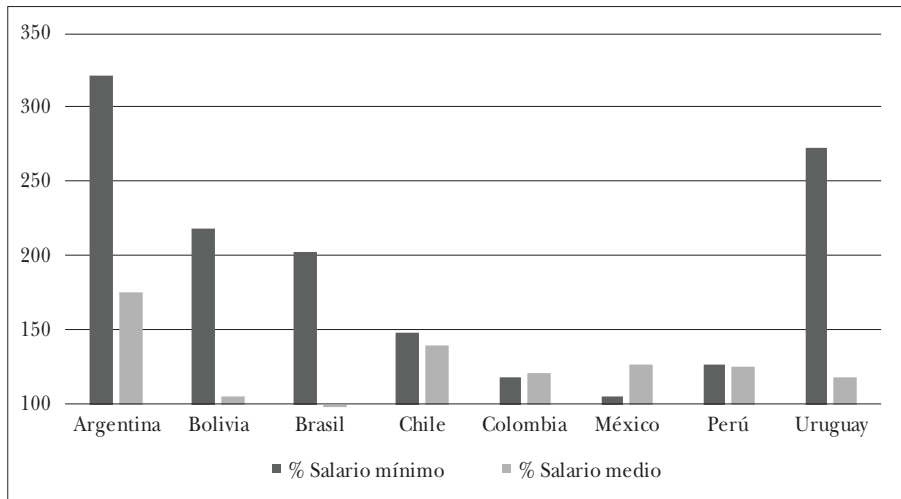

Fuente: Comisión Económica para América Latina y el Caribe, CEPAL, CEPALSTAT.

\section{La pobreza y la desigualdad}

A pesar de que la pobreza en México ha bajado proporcionalmente de 2008 a 2018 de $44.4 \%$ a $41.9 \%$, el crecimiento poblacional tiene como consecuencia que haya más pobres ahora que hace 10 años: 49.5 millones en 2008 y 52.4 millones en 2018. Es cierto que en el sexenio pasado descendió la pobreza de $45.5 \%$ a $41.9 \%$ de la población, aunque en nivel absoluto fue mínimo el cambio: 53.3 a 52.4 millones de personas. Esta situación contrasta con lo que sucedió en Brasil

${ }^{50}$ Consejo Nacional de Evaluación de la Política de Desarrollo Social, Coneval, Medición de la pobreza, México: Coneval, 2018, https://www.cone val.org.mx/Medicion/Paginas/PobrezaInicio.aspx 
entre 2000 y 2014, cuando 30 millones de individuos salieron de la pobreza, y lo que ha logrado China en los últimos 30 años, sacar de la pobreza a más de 200 millones de personas.

Otro tanto podemos decir de la desigualdad. Una sociedad más desigual implica que el crecimiento favorece más a los sectores más adinerados, por lo que no se extiende a la totalidad de la población, aumentando la demanda agregada. En la medida en que el crecimiento favorece mayormente a los más ricos que ahorran o que gastan en productos suntuarios que son, en su gran mayoría importados, se reduce el impacto sobre la demanda agregada interna.

Por otra parte, la desigualdad desestimula la oferta, porque las “...sociedades desiguales tienden a acumular menos capital humano... [y]... deprimir la demanda de mercado para los bienes producidos por sectores sujetos a rendimientos crecientes a escala" ${ }^{51}$ Lo que implica “...menos inversión en infraestructura física, educación, salud y otros bienes públicos que son esenciales al crecimiento económico".52 En contraste, una sociedad con una clase media más amplia genera una demanda mayor de productos no básicos, más sofisticados, de mayor calidad, que requieren para su manufactura una estructura productiva más compleja la cual, en caso de que sea promovida internamente (y no sólo importada, como sucedió en muchos países de América Latina en el súper boom de las commodities), pueden inducir el desarrollo. ${ }^{53}$ Además, una clase media más amplia incluye individuos con más recursos y que pueden convertirse en empresarios y transformar su capacidad de ahorro en inversiones productivas. Finalmente, también desde el lado de la oferta, dado que una sociedad desigual es más inestable sociopolíticamente, está dominada por el conflicto distributivo, que genera manifesta-

${ }^{51}$ Ros, art. cit., 2015, p. 178.

${ }^{52}$ Easterly, citado por Asian Development Bank, ADB, The Rise of Asia's Middle Class, Key Indicators for Asia and the Pacific, Manila, Filipinas, ADB, 2010, https://www.adb.org/publications/key-indicators-asia-and-pacific2010

${ }^{53}$ Banerjee y Duflo, 2008, citado en Loc. cit. 
ciones y acciones de protesta y el voto por opciones radicales, lo que desestimula la inversión).$^{54}$

En la gráfica 1 vimos cómo algunos países latinoamericanos aprovecharon el boom de las materias primas para reducir la pobreza y hacer crecer las clases medias, mientras que en México apenas se redujo la pobreza y el sector de las clases medias ha crecido escasamente. También pudieron reducir la desigualdad en un grado considerable entre 2002 y 2012 , mientras que en México las cifras se han reducido menos desde mediados de la década de 1990. ${ }^{55}$ Aunque el índice de Gini brasileño siga siendo mayor que el mexicano, lo que hace que Brasil sea un país más desigual que México, la desigualdad en aquel país se redujo significativamente desde 1996.

GRÁFICA 14

Indíce de Gini, 1996-2016

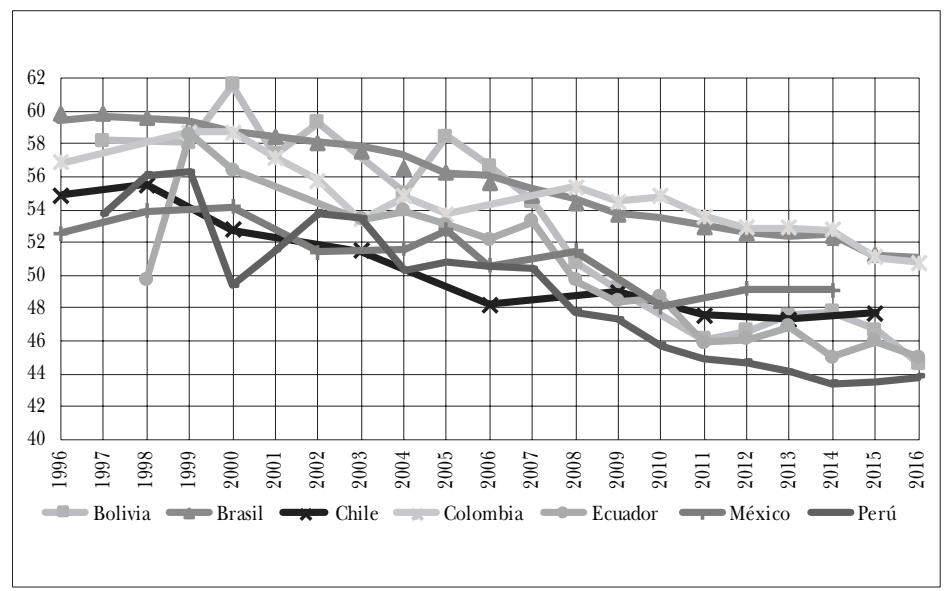

Fuente: World Bank Databank y Comisión Económica para América Latina y el Caribe, CEPAL, CEPALSTAT.

${ }^{54}$ Rodrik, citado por ADB, ibid.; Alberto Alesina, "Political Models of Macroeconomic Policy and Fiscal Reforms", en S, Haggard y S. Webb (eds.), Voting for Reform, Oxford, University Press, 1994.

55 Therborn, art. cit.; Fritz y Lavinas, op. cit.; Boyer, art. cit. 
Las fuentes de crecimiento futuro: las políticas ambientales y la transición energética

La economía presente se proyecta (o no) al futuro mediante el cuidado de su entorno natural, del que dependerán las posibilidades económicas venideras. No es posible concluir un balance del sexenio sin referir, aunque sea someramente, en qué contribuyó la pasada administración para asegurar el futuro de las riquezas naturales con las que todavía cuenta el país. Cabe empezar con la afirmación de que ninguno de los gobiernos mexicanos de las últimas décadas se ha preocupado seriamente por el medio ambiente. En el caso del sexenio que nos ocupa, ninguno de los macroproyectos de infraestructura fue sometido a una seria evaluación de impacto ambiental. Un ejemplo de ello fue el del Nuevo Aeropuerto Internacional de la Ciudad de México (NAICM), que estaba en proceso de construcción en el lago de Texcoco. Este proyecto adolecía de muchas fallas, la principal era que se estaba construyendo en el antiguo lago, que a pesar de no ser ya un lago, es una depresión con respecto a los territorios colindantes, lo que permite que ese terreno capte agua de lluvia la cual, por una parte, alimenta los acuíferos y, por la otra, impide que se inunden las zonas más bajas de la Ciudad de México. Asimismo, iba a ser necesario secar el lago Nabor Carrillo debido a que atrae numerosas aves migratorias que son un riesgo para el tránsito aéreo.$^{56}$ El gobierno de Peña Nieto tampoco hizo mucho por mejorar el uso de los ríos y las aguas nacionales. Como se sabe, la mayoría de los ríos y las fuentes de agua del país están contaminadas, y se desperdicia alrededor de $40 \%$ del agua que se utiliza tanto para el consumo como para el riego. Por otra parte, la mayor parte del agua que se utiliza en México no se trata o recicla por las empresas o las administraciones de las ciudades.

${ }^{56}$ A. Bizberg, "Country Profile: Mexico" (informe sin publicar), México, The Nature Conservacy, TNC, 2019. 
En el caso de las selvas y bosques, que son un importante medio de captación de carbono, el gobierno se comprometió a frenar su destrucción y, en efecto, se ha mitigado levemente. Entre 1993 y 2011, la superficie forestal decreció en $4 \%$, principalmente debido a su uso agrícola e incendios. En el periodo que va de 2005 a 2010 el país se deforestó a un ritmo de 116900 ha al año, mientras que entre 2010 y 2015 el ritmo de reducción fue de 91600 ha anuales. ${ }^{57}$

El gobierno de Peña Nieto fue muy activo en declarar vastos territorios como áreas naturales protegidas (ANP) y, en efecto, triplicó la superficie para llegar a 91 millones de ha, con 114 ANP. No obstante, en total contradicción con este propósito, en 63 de estas áreas se han otorgado concesiones mineras. ${ }^{58}$ De hecho, las empresas mineras junto con los desarrollos turísticos son los que más desastres causan a la ecología, las primeras por ser a cielo abierto y las segundas por situarse sobre los manglares, destruyéndolos.

Por otra parte, las empresas que contaminan o destruyen zonas protegidas rara vez son sancionadas y, cuando lo son, las multas que se le imponen son minúsculas con respecto a los daños causados y al beneficio que representa para ellas, por lo que no es en absoluto un desaliento, sino todo lo contrario. Hubo varios casos de hoteles que destruyeron un manglar, que construyeron un muelle y afectaron una barrera de coral, pero el caso más sonado de impunidad por ecocidio fue el de una mina del conglomerado minero más grande del país, Minera México. Esta empresa derramó sustancias toxicas en el río Sonora y el poblado de Bacanuchi y, más grave aún, intentó ocultar el daño. Como resultado de esto último, la población del área siguió bebiendo y dando de beber a su ganado el agua contaminada, con lo que el daño se volvió mayúsculo. Una vez que se dio el aviso y que la compañía fue

57 Loc. cit.

58 Leticia Merino, "La Semarnat que dejan Peña, Pacchiano y el PVEM", Aristegui Noticias, 17 de agosto de 2018, https://aristeguinoti cias.com/1708/mexico/la-semarnat-que-dejan-pena-pacchiano-y-elpvem-articulo/ 
juzgada, se le multó con 23.5 millones de pesos -cifra ridícula para una empresa que gana miles de millones de dólares al año- por un daño incalculable y duradero al medio ambiente que afectó al menos a 22000 personas en siete municipios y que fue considerado por la propia administración de Peña Nieto como "la peor catástrofe ambiental en la industria minera del país en los tiempos modernos". ${ }^{59}$

En lo que se refiere a las nuevas fuentes de energía limpia que se proponen combatir el cambio climático, el gobierno mexicano ha logrado ubicarse discursivamente como un líder activo a nivel internacional. En la conferencia de la cop22 en París, el gobierno de Peña Nieto se comprometió a reducir las emisiones de carbono a la mitad para 2050, tomando como base el año 2000. Se comprometió a incluir en su matriz 30\% de energía limpia en 2021, y 25\% en 2024. Para ello, estableció un impuesto a la emisión de carbono y, aprovechando que se liberalizó el mercado con la reforma energética, llevó a cabo un número considerable de subastas para la instalación de fuentes de energías renovables (principalmente solares y eólicas). Eso no ha signficado que en los hechos esté avanzando mucho. ${ }^{60}$

En primer lugar, el impuesto al carbono (básicamente el IEPS que se cobra a las gasolinas) que debía haber servido como recursos para dedicar a proyectos ecológicos, han entrado directamente al presupuesto corriente del gobierno, sin etiqueta. Por otra parte, el país es uno de los que menos recursos obtiene por medio de impuestos medioambientales: sólo $0.06 \%$ del PIB en $2014 .{ }^{61}$ Finalmente, a pesar de que las subastas eléctricas han aumentado considerablemente, la generación de energía de fuentes renovables no hidráulicas es menor que en Brasil, crece con menor velocidad que Chi-

59 Greenpeace México, "Catástrofes, la marca del sexenio de Peña Nieto en materia ambiental”, Greenpeace México (sitio de internet), 3 de septiembre de 2018, https:/ /www.greenpeace.org/mexico/noticia/931/ catastrofes-la-marca-del-sexenio-de-pena-nieto-en-materia-ambiental/

${ }^{60}$ A. Bizberg, art. cit.

${ }^{61}$ Loc. cit. 
na y es infinitamente menor a la de un pequeño país centroamericano: Costa Rica (véase la gráfica 15). Por otro lado, la misma reforma peñista permite e incentiva el fracking, un método altamente contaminante, que ha sido desechado en varios países, entre ellos Francia.

\section{GRÁFICA 15}

Producción de energía de fuentes renovables, excluyendo hidroeléctricas (\% del total)

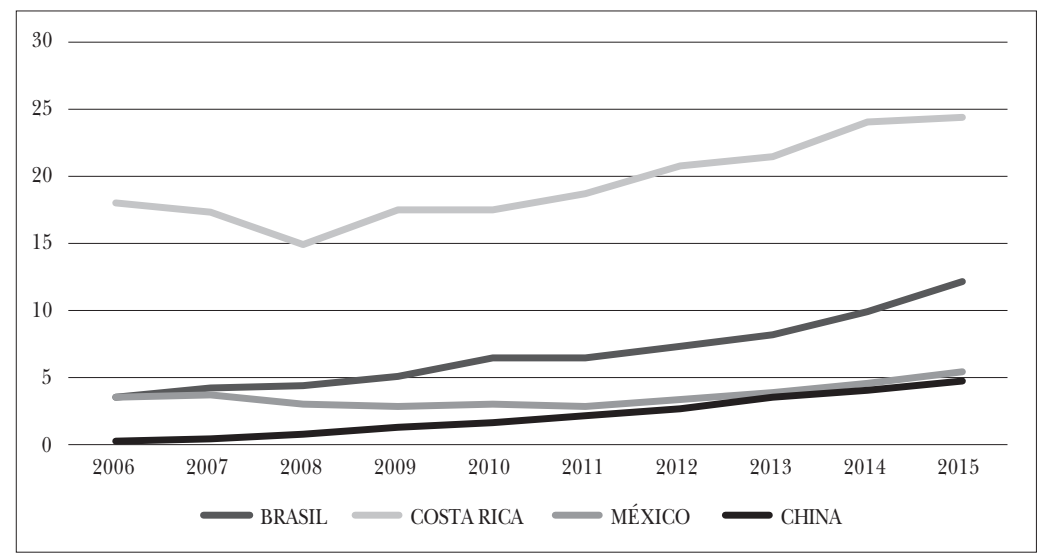

Fuente: World Bank Databank.

En otro registro, el presupuesto de la Secretaría de Medio Ambiente y Recursos Naturales (Semarnat) sufrió un recorte superior al $50 \%$ entre los años 2015 y 2018, convirtiéndose así en una de las tres dependencias que mayores recortes tuvo durante la administración de Peña Nieto. Además, en 2017 se recortaron en $21 \%$ los recursos destinados a combatir el cambio climático en comparación con el año anterior. $^{62}$

${ }^{62}$ Greenpeace México, art. cit. 
CONTINUIDAD O GIRO RADICAL: ALGUNAS PISTAS SOBRE EL NUEVO GOBIERNO

La intención primera del nuevo gobierno de AMLo ha sido el final del liberalismo y una política social que se basa en la idea de que "para el bien de todos, primero los pobres", lo cual puede leerse como un proyecto que se aleja del modelo de subcontratación internacional que ha seguido el país durante más de tres décadas y se orienta hacia la economía interna. Esto requeriría una mayor intervención estatal, tanto en lo que se refiere al gasto público, la inversión, una política industrial activa, así como la redistribución para aumentar la demanda interna. Si no se dan estos cuatro elementos en conjunto, el intento por alejarse del modelo fracasará.

Lo primero que hizo el nuevo gobierno fue en el sentido de la redistribución: aumentó el salario mínimo en un 16\% a nivel nacional y lo duplicó en la frontera norte. Por otra parte, el gobierno universalizó ${ }^{63}$ y aumentó (de 600 a 1275 pesos al mes) la pensión no contributiva de los mayores de 68 años. El gobierno de AMLo ha propuesto crear un sistema de salud verdaderamente universal (el seguro popular no lo era); no obstante, la cantidad que se invertirá este año no es en absoluto suficiente para fortalecerlo significativamente. Existe, además, un programa de becas de capacitación empresarial, de 3500 pesos al mes, durante un año, para 900000 jóvenes, así como becas para estudiantes en todos los niveles escolares, que sustituyen a Prospera.

A pesar de que estos programas sociales representan una derrama importante de recursos para el consumo, al mismo tiempo, y contrarrestándola, el gobierno de AMLO ha reducido su gasto y su inversión. Ha implementado un muy amplio y radical programa de austeridad, despidiendo a miles de funcionarios de todos los rangos, recortando el gasto de prácticamente todas las secretarías de Estado, dejando de canalizar recursos a diversas organizaciones sociales que colaboraban

${ }^{63}$ A pesar de que muchos adultos mayores aún no la han recibido. 
con el gobierno en políticas sociales, entre otras. Por otra parte, como ha pasado en anteriores gobiernos cuando toman posesión, los macroproyectos de infraestructura se han atrasado, lo que se añade a la penuria del gasto del gobierno. Todo ello, evidentemente ha afectado la demanda agregada más que al beneficio de los programas sociales. A esto se añade la baja de la inversión privada como resultado de que está esperando señales claras de hacia dónde se dirige el país y, en el caso de la inversión extranjera, lo que sucederá con el nuevo tratado de libre comercio y con las posturas proteccionistas del presidente de Estados Unidos. El resultado ha sido una desaceleración de la economía.

Quizá esto sea resultado de un inicio del gobierno que se verá revertido en el futuro cercano por los macroproyectos: un segundo aeropuerto en la Ciudad de México, una línea ferroviaria en el istmo de Tehuantepec, que unirá el océano Atlántico y el Pacífico, un tren turístico-comercial en la península de Yucatán y la refinería Dos Bocas, en Tabasco, proyectos estos últimos orientados a promover el empleo en las regiones más pobres del país: Chiapas, Oaxaca y Tabasco. No obstante, muchos autores han indicado el reducido impacto que tienen los grandes proyectos intensivos en capital en la creación de empleos permanentes, es decir, en la integración de la población al mercado. ${ }^{64}$

La insistencia en estos macroproyectos contrasta con la falta de definición de política industrial, aparte de vagas referencias al apoyo a las pequeñas y medianas empresas en el Plan Nacional de Desarrollo, no existe un plan para la expansión del banco de inversión estatal o cambios en sus reglas operativas, ni de una política para estimular sectores económicos que permitan reconstruir las cadenas productivas, ni tampoco una política científica y de innovación para aumen-

${ }^{64}$ Juliana Martínez Franzoni y Diego Sánchez-Ancochea: “The Double Challenge of Market and Social Incorporation: Progress and Bottlenecks in Latin America", desiguALdades.net (Research Network on Interdependent Inequalities in Latin America), Working Paper Series No. 27 (2012). 
tar la productividad y la especialización con el objeto de que la economía mexicana logre crear más y mejores empleos. Hemos analizado cómo el crecimiento económico no depende sólo de la inversión estatal, por más elevada que ésta sea, sino que es necesario sentar las condiciones adecuadas para que la iniciativa privada invierta. Y, por la experiencia de otros países, hemos visto que la distribución, sin una política industrial que integre cadenas productivas y aumente el valor agregado de los productores nacionales y de su capacidad tecnológica, conduce a un mayor nivel de importaciones y eventualmente a una crisis de cuenta corriente.

Además, hay una duda razonable con respecto a la posibilidad real de que el gobierno actual pueda financiar sus políticas de bienestar y sus macroproyectos de infraestructura con la austeridad, el ahorro y la lucha contra la corrupción. Con más razón cuando plantea que el presupuesto debe ser equilibrado y austero, absolutamente ortodoxo, sin incurrir en un déficit presupuestario, y de que ha prometido no aumentar su deuda. Parece evidente para muchos economistas y socioeconomistas que el país tiene espacio para aumentar el déficit presupuestario y la deuda, y que debe rechazar la política de austeridad que tanto daño ha hecho a muchos países europeos, tanto en términos económicos, sociales, como políticos. Además, aun más importante, es necesario que el gobierno considere una reforma fiscal profunda y progresiva para resolver la bajísima recaudación del Estado; pero una reforma distinta de las que se han aplicado hasta ahora que sólo han afectado a las clases medias y no a las grandes empresas y al sector financiero, ya que, como hemos analizado, el consumo de las clases medias es central para el desarrollo de cualquier país.

Finalmente, tampoco es claro que exista la voluntad de aplicar políticas serias y eficaces hacia el medio ambiente y la transición energética. Aunque el gobierno de AMLO canceló la construcción del aeropuerto de Texcoco y declaró que prohibió el fracking, es un gobierno que apuesta todo a la industria petrolera y que ha cancelado las subastas de generación de 
energías renovables. Es más, se ha comprometido a comprar una cantidad muy grande de carbón para las plantas de generación de electricidad de la CFE del norte del país, plantea construir una refinería en Tabasco y aumentar la extracción de petróleo. Y, al igual que en los últimos años del gobierno de Peña Nieto, ha reducido el presupuesto de la Secretaría de Medio Ambiente.

Por otra parte, los proyectos de los trenes transístmico y maya, que se construirán en la península de Yucatán, han sido criticados por su impacto sobre el medio ambiente y la vida de las comunidades indígenas, que en muchos casos son los guardianes de la naturaleza, o podrían serlo si todavía no lo son, con políticas públicas adecuadas. Se esperaría que un gobierno que se propone una transformación radical del país debería orientarse a la transición ecológica e invertir en energías renovables, en lugar de esforzarse por hacerlo en energías fósiles. Pero, como la mayoría de los gobiernos de izquierda, el mexicano considera que el país tiene demasiados problemas sociales como para poder cuidar de la ecología, sin tener en cuenta que la destrucción del medio ambiente afectará en primer lugar a los más pobres.

Hay otra razón para dejar de lado los macroproyectos, y es que el énfasis debería de ponerse en la infraestructura que ya existe, y que es deficiente, así como en financiar la educación, la salud, el agua potable de las poblaciones que carecen de ésta, con el objeto de mejorar la vida de millones de mexicanos y su posibilidad de salir de la pobreza y para que el país pueda desarrollarse, como hicieron los países de Asia que avanzaron en esa línea.

Finalmente, en tiempos recientes, el gobierno ha criticado a la principal institución que evalúa el resultado de sus políticas sobre el bienestar de la población, en términos de la pobreza, la desigualdad, la salud, la educación, y ha incluso amenazado con cancelarla. No obstante, es crucial entender que para un gobierno que pretende realmente transformar a México y no simular el cambio, como los anteriores, la evaluación es aun más importante porque resulta fundamental conocer a cabali- 
dad los efectos de sus políticas y modificarlas si no están teniendo el resultado esperado.

ApÉndice

Datos fundamentales del sexenio

\begin{tabular}{|c|c|c|c|c|c|c|}
\hline Variable & 2012 & 2013 & 2014 & 2015 & 2016 & 2017 \\
\hline Crecimiento PIB* & 3.6 & 1.4 & 2.8 & 3.3 & 2.9 & 2 \\
\hline PIB per cápita* & 16,049 & 16,848 & 17,482 & 17,239 & 17,770 & 18,258 \\
\hline Crecimiento PIB per cápita* & 2.2 & -0.1 & 1.4 & 1.9 & 1.6 & 0.8 \\
\hline Crecimiento exportaciones* & 6.5 & 1.4 & 7 & 8.4 & 3.5 & 3.8 \\
\hline Crecimiento importaciones & 5.6 & 5.4 & 2.1 & 5.9 & 2.9 & 6.4 \\
\hline Balance de cuenta corriente* & $-18,572$ & $-31,012$ & $-23,998$ & $-29,774$ & $-23,321$ & $-19,354$ \\
\hline Creación de capital fijo* & 23.9 & 22.5 & 21.9 & 23.3 & 23.7 & 23.1 \\
\hline Ingresos fiscales* & 9.8 & 10.3 & 10.6 & 12.8 & 13.5 & 13.1 \\
\hline Consumo del gobierno* & 11.9 & 12.2 & 12.2 & 12.3 & 12.1 & 11.8 \\
\hline Deuda pública** & 45.9 & 48.9 & 52.8 & 56.8 & 54.0 & 53.6 \\
\hline Deuda externa & $349,269.4$ & $406,227.1$ & $442,413.9$ & $426,905.1$ & $422,473.3$ & $455,058.1$ \\
\hline Servicio de deuda* & $70,837.8$ & $41,596.7$ & $49,390.1$ & $54,148.4$ & $79,068.1$ & $62,749.5$ \\
\hline $\begin{array}{l}\text { Tasa de cambio* } \\
(2010=100)\end{array}$ & 96.6 & 102.2 & 101.2 & 90.7 & 79.0 & 80.8 \\
\hline inflación* & 4.1 & 3.8 & 4 & 2.7 & 2.8 & 6 \\
\hline Asegurados IMSS*** & $16,062,043$ & $16,525,061$ & $17,239,587$ & $17,884,033$ & $18,616,624$ & $19,418,455$ \\
\hline
\end{tabular}

Fuentes:* World Bank; ** FMI; ***IMss.

\section{REFERENCIAS BIBLIOGRÁFICAS}

Asian Development Bank, ADB, The Rise of Asia's Middle Class, Key Indicators for Asia and the Pacific, Manila, Filipinas, ADB, 2010, https://www.adb.org/publications/key-indicators-asia-and-pa cific-2010

Alesina, Alberto, "Political Models of Macroeconomic Policy and Fiscal Reforms", en S. Haggard y S. Webb (eds.), Voting for Reform, Oxford, University Press, 1994.

BanerJee, Abhijit y Esther Duflo, "What is middle class around the world?", Journal of Economic Perspective 22, núm. 2 (2008), pp. 3-28. 
Bertelsmann Transformation Index, BTI2018 Transformation Index (World Bank), https://www.bti-project.org/en/data/ (consulta de agosto de 2019).

Bizberg, A., "Country Profile: Mexico" (informe sin publicar), México, The Nature Conservacy, TNC, 2019.

Bizberg, A., "Presentación en la Universidad Iberoamericana" (manuscrito), México, 2019.

Bizberg, Ilán (coord.), Las variedades del capitalismo en América Latina, México, El Colegio de México, 2015.

Bizberg, Ilán, Diversity of Capitalisms in Latin America, Londres, Palgrave-Macmillan, 2019.

Blecker, Robert y Gerardo Esquivel, "NAFTA, trade and development”, California, Universidad de San Diego, 2010, 41 pp.

Boschi, Renato Raúl y Carlos Eduardo Santos Pinho, "Desarrollo capitalista, austeridad fiscal y democracia en Brasil”, en Alberto Aziz e Ilán Bizberg, Variedades de capitalismos en crisis, México, El Colegio de México (en prensa).

Boyer, Robert, "Is More Equality Possible in Latin America? A Challenge in a World of Contrasted but Interdependent Inequality Regimes", desiguALdades.net Working Paper Series 67, Berlín, Freie Universität Berlin, 2014.

Boyer, Robert, "¿Qué significa la creciente variedad de capitalismos contemporáneos para la teoría económica?”, en Alberto Aziz e Ilán Bizberg, Variedades de capitalismo en crisis, México, El Colegio de México (en prensa).

Bresser Pereira, L. C. y Paulo Gala, "Macroeconomía estructuralista del desarrollo: ¿un segundo momento del estructuralismo latinoamericano?”, en Jose Luis Calva (coord.), Análisis Estratégico para el Desarrollo, vol. 4 (2012), pp. 245-272.

Bresser Pereira, L. C., "Régimen de política económica liberal y cuasi-estagnación en Brasil desde 1990”, en Alberto Aziz e Ilán Bizberg, Variedades de capitalismo en crisis, México, El Colegio de México (en prensa, 2019).

Clavellina Miller, José Luis y Víctor Ortega Olvera, "Reforma energética y nuevo régimen fiscal del sector de hidrocarburos", Cuaderno de investigación, México, Senado de la República, Instituto Belisario Dominguez, 2015. 
Comisión Económica para América Latina y el Caribe, CEPAL, cepalstat, Bases de Datos y Publicaciones Estadísticas Comisión Económica para América Latina y el Caribe (sitio de internet), https://estadisticas.cepal.org/cepalstat/Portada.html?idi oma=spanish

Consejo Nacional de Evaluación de la Política de Desarrollo Social, Coneval, Diagnóstico de productividad y análisis de los avances del Programa para Democratizar la Productividad 2013-2018, México, Coneval, 2018.

Consejo Nacional de Evaluación de la Política de Desarrollo Social, Coneval, Medición de la pobreza, México, Coneval, 2018, https://www.coneval.org.mx/Medicion/Paginas/PobrezaInicio.aspx

Cortés, Fernando, "Medio siglo de desigualdad en el ingreso en México", Economía UNAM, vol. 10, núm. 29 (2013).

Dussel Peters, Enrique, "La manufactura en México: condiciones y propuestas en el corto, mediano y largo plazo", en José Luis Calva (coord.), Nueva política de industrialización. Vol. 7 de Análisis Estratégico para el desarrollo, México, Juan Pablos Editor, Consejo Nacional Universitario, 2011, 34 pp.

Easterly, William, "The Middle Class Consensus and Economic Development”, Journal of Economic Growth, 6, núm. 4 (2001), pp. 317-335.

ESQUIVEL, Gerardo, "De la inestabilidad macroeconómica al estancamiento estabilizador: el papel del diseño y la conducción de la política económica", en Nora Lustig, Los grandes problemas de México. IX Crecimiento Económico y Equidad, México, El Colegio de México, 2010.

Evans, Peter, Embedded Autonomy. States and industrial transformation, Princeton, New Jersey, Princeton University Press, 1995.

Martínez Franzoni, Juliana y Diego Sánchez-Ancochea, "The Double Challenge of Market and Social Incorporation: Progress and Bottlenecks in Latin America", desiguALdades.net (Research Network on Interdependent Inequalities in Latin America), Working Paper Series núm. 27 (2012). 
Fritz, Barbara y Lena Lavinas, A Moment of Equality for Latin America? Challenges for Redistribution, Surrey and Burlington, Ashgate, 2015.

García, Karen, "Bajan carga fiscal de Pemex y aporte a ingresos públicos", El Economista, 22 de julio de 2019, https://www. eleconomista.com.mx/empresas/Bajan-carga-fiscal-de-Pemexy-aporte-a-ingresos-publicos-20190723-0010.html

Greenpeace México, "Catástrofes, la marca del sexenio de Peña Nieto en materia ambiental", Greenpeace México (sitio de internet), 3 de septiembre de 2018, https:/ /www.greenpeace. org/mexico/noticia/931/catastrofes-la-marca-del-sexeniode-pena-nieto-en-materia-ambiental/

Guillén Romo, H., "México: del desarrollo 'hacia adentro' al desarrollo 'hacia fuera'", en Jose Luis Calva (coord.), Análisis estratégico para el desarrollo, vol. 3, México, Juan Pablos Editor, 2012, pp. 245-283.

Guillén Romo, H., "México, ejemplo de las políticas anti-desarrollo del Consenso de Washington", Estudos Avançados, 26, núm. 75 (2012).

Haggard, Stephan, Pathways from the Periphery. The Politics of Growth in the Newly Industrializing Countries, Nueva York, Cornell University Press, 1990.

Hoshino, T., Red de proveeduría de la industria automotriz en México: ¿es posible la incorporación de las empresas mexicanas?, Guadalajara, Universidad de Guadalajara, 2018.

IbARra, C., "La paradoja del crecimiento lento de México", Revista de la CEPAL, núm. 95 (2008).

Ibarra, C., "México: la maquila, el desajuste monetario y el crecimiento impulsado por las exportaciones", Revista CEPAL, 104, (agosto de 2011), pp. 199-215.

Instituto Belisario Domínguez, "La reforma hacendaria a cuatro años de su implementación. Resultados y propuestas", Notas estratégicas, núm. 27 (julio de 2018).

Lecuona, R. V., "Inclusión financiera de las pequeñas y medianas empresas en México: el papel de la banca de desarrollo", en Esteban Pérez Caldentey y Daniel Titelman (eds.), La inclusión financiera para la inserción productiva y el papel de la banca de desa- 
rrollo, Libros de la CEPAL, núm. 153 (LC/PUB.2018/18-P), Santiago, Comisión Económica para América Latina y el Caribe, 2018.

Manrique Campos, Irma, "Banca de desarrollo en México: un futuro necesario", en J. L. Calva, Agenda para el Desarrollo, Vol. 6: Financiamiento del crecimiento económico, México, Porrúa-UnAm, 2007, pp. 100-116.

Marques Pereira, Jaime y Bruno Théret, "Mediaciones institucionales de regulación social y dinámicas macroeconómicas: los casos de Brasil y México”, en Carlos Alba e Ilán Bizberg (eds.), Democracia y globalización en México y Brasil, México, El Colegio de México, 2004.

Marques Pereira, Jaime y Miguel Bruno, "Path dependence blocking the emergence of a new type of capitalism favoring redistribution in Brazil: A new view on the possibility of a developmental coalition", Francia, Université d'Amiens (manuscrito), 2015.

Merino, Leticia, "La Semarnat que dejan Peña, Pacchiano y el PVEM", Aristegui Noticias, 17 de agosto de 2018, https:/ / ariste guinoticias.com/1708/mexico/la-semarnat-que-dejan-pena pacchiano-y-el-pvem-articulo/

"Mexico's Moment", The Economist, 21 de noviembre de 2012 https://www.economist.com/news/2012/11/21/mexicos-mo ment

Moreno BRID, J. C., "Cambio estructural para el crecimiento económico: grandes pendientes de la economía mexicana”, en Rolando Cordera (coord.), Más allá de la crisis. El reclamo del desarrollo, México, FCE, 2015.

Moreno Brid, J.C., "Política macro e industrial para un cambio estructural y crecimiento: gran pendiente de la economía mexicana", Revista Problemas del Desarrollo, 187, núm. 47 (abriljunio de 2016), pp. 57-78.

Palma, José Gabriel, "The seven main 'stylized facts' of the Mexican economy since trade liberalization and NAFTA", Industrial and Corporate Change, vol. 14, núm. 6 (2005), pp. 941-991.

Puyana, Alicia y José Romero Tellaeche, México. De la crisis de la deuda al estancamiento económico, México, El Colegio de México, 2009 . 
RoDriK, D., “¿Por qué hay tanta inseguridad económica en América Latina?”, Revista de la CEPAL, núm. 73 (2001), pp. 7-31.

Ros, J., "Las trampas del lento crecimiento y tres reformas recientes", en Rolando Cordera (coord.), Más allá de la crisis. El reclamo del desarrollo, México, FCE, 2015.

Ros, J., "La economía mexicana en 2016: tendencias y perspectivas”, Revista de Economía Mexicana, Anuario UNAM, núm. 2, 2017.

"Saving Mexico", Time, 24 de febrero de 2014.

Soria Murillo, Víctor, Saldos perversos de la política neoliberal en México, UAM-Colofón, 2017.

Stampini, Marco, Marcos Robre, Mayra Sáenz, Pablo Ibarrarán y Nadin Medellín, "Pobreza, vulnerabilidad y la clase media en América Latina”, Working Paper, núm. 591, BID, 2015.

Stockhammer, Engelbert, "Crecimiento basado en los salarios: introducción”, en Hacia una recuperación sostenible: por una política de crecimiento basada en los salarios, Boletín Internacional de Investigación Sindical, Ginebra, orT, vol. 3, núm. 2 (2011).

Therborn, Göran, "Moments of Equality-Today's Latin America in a Global Historical Context”, en Barbara Fritz y Lena Lavinas, A Moment of Equality for Latin America? Challenges for Redistribution, Surrey and Burlington, Ashgate, 2015.

Torre, A. de la, A. Ize, y S. L. Schmukler, Financial development in Latin America and the Caribbean. The Road Ahead, Washington, DC, IBRD, World Bank, 2012.

World Bank Databank, https://databank.worldbank.org/home. aspx (consulta de agosto de 2019). 